\title{
Enhancement of Induction Motor Dynamics Using a Novel Sensorless Predictive Control Algorithm
}

\author{
Hamdi Echeikh ${ }^{1}$, Mahmoud A. Mossa ${ }^{2, * D}$, Nguyen Vu Quynh ${ }^{3, * \mathbb{D}}$, Abdelsalam A. Ahmed ${ }^{4}$ \\ and Hassan Haes Alhelou ${ }^{5, *(D)}$
}

1 Department of Electrical Engineering, National Engineering School of Monastir, Monastir 5035, Tunisia; hamdi.engineer.nl@gmail.com

2 Electrical Engineering Department, Faculty of Engineering, Minia University, Minia 61111, Egypt

3 Electrical and Electronics Department, Lac Hong University, Dong Nai 810000, Vietnam

4 Electrical Power and Machines Engineering Department, Faculty of Engineering, Tanta University, Tanta 31511, Egypt; abdelsalam.abdelsalam@f-eng.tanta.edu.eg

5 Department of Electrical Power Engineering, Faculty of Mechanical and Electrical Engineering, Tishreen University, Lattakia 2230, Syria

* Correspondence: mahmoud_a_mossa@mu.edu.eg (M.A.M.); vuquynh@lhu.edu.vn (N.V.Q.); h.haesalhelou@gmail.com (H.H.A.)

check for updates

Citation: Echeikh, H.; Mossa, M.A.; Quynh, N.V.; Ahmed, A.A.;

Alhelou, H.H. Enhancement of Induction Motor Dynamics Using a Novel Sensorless Predictive Control Algorithm. Energies 2021, 14, 4377. https://doi.org/10.3390/en14144377

Academic Editor: Daniel Chindamo

Received: 18 June 2021

Accepted: 17 July 2021

Published: 20 July 2021

Publisher's Note: MDPI stays neutral with regard to jurisdictional claims in published maps and institutional affiliations.

Copyright: (C) 2021 by the authors. Licensee MDPI, Basel, Switzerland. This article is an open access article distributed under the terms and conditions of the Creative Commons Attribution (CC BY) license (https:// creativecommons.org/licenses/by/ $4.0 /)$.

\begin{abstract}
The paper introduces a novel predictive voltage control (PVC) procedure for a sensorless induction motor (IM) drive. In the constructed PVC scheme, the direct and quadrature $(d-q)$ components of applied voltages are primarily managed instead of controlling the torque and flux as in the classic predictive torque control (PTC) technique. The theoretical basis of the designed PVC is presented and explained in detail, starting from the used cost-function with its relevant components. A comprehensive performance comparison is established between the two controllers, from which the superiorities of the designed PVC over the PTC approach can be easily investigated through the reduced ripples, reduced computation time, and faster dynamics. To sustain the system's reliability, a combined Luenberger-sliding mode observer (L-SMO) is designed and verified for different operating speeds for the two controllers. The Luenberger component is concerned with estimating the stator current, rotor flux, and rotor speed. Meanwhile, the sliding mode term is used to ensure the system's robustness against any disturbance. The verification of PVC's validity is outlined through performing a performance analysis using the Matlab/Simulink software. The results illustrate that the IM dynamic is significantly improved when considering the constructed PVC compared with the IM dynamics under the PTC. In addition, the designed L-SMO observer has effectively proved its ability to achieve definite parameters and variable estimation.
\end{abstract}

Keywords: predictive control; torque control; IM; sensorless control; Luenberger observer; SMO; state estimation

\section{Introduction}

The DTC and FOC techniques are considered the most utilized controllers for obtaining high performance of several types of electric machines [1-10]. The DTC control depends mainly on the direct variation of stator flux via the proper selection of applied stator voltage vectors which are selected from specified tables (i.e., look up tables) after comparing the desired torque and flux values with their relevant actual ones [1-5]. Meanwhile, the FOC depends on regulating the direct and quadrature stator current components in an effort to obtain an indirect control of flux and torque, respectively [6-10]. In a comparison between these two schemes, it is found that the DTC is much simpler and faster in dynamic response than the FOC, but on the other hand, it is verified that the FOC exhibits fewer ripples when compared with the DTC.

As an attempt to improve the DTC dynamics, different studies were presented [11-16]. In $[11,12]$, the DTC scheme is combined with space vector PWM (SVPWM) in order to get 
a fixed switching frequency and help in limiting the associated torque and flux ripples. In $[13,14]$, the study proposed incorporating a fuzzy controller instead of the classic PI speed regulator in order to enhance the dynamics. In $[15,16]$, modified look up tables were utilized which contributed effectively towards reducing the ripples of controlled variables. However, the improvements achieved with these modifications, but on the other hand the simplicity of the DTC controller was lost.

In a similar way, different studies were concerned with improving the dynamic response of FOC controllers used with IM drives [17-20]. The study in [17] proposed a flux estimator for ensuring the stable operation of the controller at all operating frequencies, but it ignored the system's complexity considerations. In [18], a field weakening approach was incorporated in the indirect FOC scheme to ensure a good transient behavior and high energy conversion efficiency at the same time. This has been realized through formulating the reference $d$-axis stator current of three components: load compensating, no-load and transient compensating components. In [19], the authors replaced the control of $d-q$ stator currents by controlling directly the reactive and real powers input to the motor in order to give the controller more robustness. However, the transient behavior of the controller was not smooth. In [20], the authors replaced the classic PI current regulators in FOC with adaptive neuro-fuzzy controllers. Notwithstanding the improved dynamics of the drive, the system complexity was remarkable due to the need for the precise determination of the controllers' gains.

In order to combine the advantages of two control schemes (DTC and FOC), and avoid the shortages in them as much as possible, the model predictive control (MPC) was introduced and applied in different forms for IM drives with its different configurations [21-29]. Some of the MPC forms applied to the electric drives are the predictive torque control (PTC) [21-24] and predictive current control (PCC) [25-29], which are considered as a transpose to the DTC and FOC, respectively. In the PTC, the voltages tables and hysteresis comparators used in DTC are replaced by a simple and flexible cost function form which combines the torque error and flux error multiplied to a weighting factor $\left(W_{f}\right)$. On the other hand, the PCC replaces the PI current regulators used in FOC with a simple optimization function consists of two terms of the same category which are the errors between the reference and actual stator or rotor current $d-q$ components without using a weighting value similar to that in PTC. Thus, through checking the obtained advantages when considering the PTC and PCC, it is found that, in PTC, the ripples are effectively reduced in comparison with the DTC while maintaining the simplicity at the same time. Meanwhile, in the PCC, the system's complexity is effectively reduced, and faster dynamics are realized comparing with the FOC's performance [30,31].

Despite the improved dynamic characteristics obtained with the MPC schemes (i.e., PTC and PCC), there are still some shortages related to their operations. For example, in the PTC, however the ripples are exhibiting lower values compared with the DTC, but they are not completely eliminated. This phenomenon can be inferred to several reasons. The first one can be referred to the in accurate selection of applied voltages. The inappropriate voltage selection can be explained through selecting a voltage vector which is applied for the overall sampling time, and it may occur that a torque or flux variation appears during this sampling interval which requires updating the selected voltage and which is not fulfilled in the PTC, which finally resulting in enlarging the torque/flux deviations and consequently increasing the ripples. Another reason is related to the wrongly selected weighting value $\left(W_{f}\right)$. This value plays a very important role in balancing the weight of flux respecting to the torque variation, and thus any deviation from its optimal value causing large ripples. The selection of suitable $W_{f}$ values were performed by two ways: offline using trial and error [32], and online using optimization techniques [32,33]. Offline selection is not an accurate tool. Meanwhile, the online updating consumes extra time during the execution, which adds computational burdens on the used microcontrollers.

Similar to the PTC, the PCC method suffered from some shortages such as it is much time consuming than the FOC and PTC itself. This feature is present due to the need for 
predicting the current components in each control cycle [34,35]. Moreover, the current prediction depends mainly on the machine model, which makes it very sensitive to the parameters change. This is in addition to the measuring noise effect [36]. All these factors negatively affect the accuracy of the controller due to the inaccurate current prediction, which finally results the generation of some ripples in the controlled variables (however, the ripples here are lower than the PTC but higher than FOC).

Great efforts were made to avoid the shortages of PTC and PCC to obtain improved system dynamics. For example, in [34-37], adaptive estimators were used to improve the flux estimation and hence reduce the flux and torque ripples in the used PTC schemes. Improved dynamics were obtained, but on the other side, the complexity is enlarged. In $[38,39]$, the researchers proposed PTC schemes in which the sampling time is divided so that multiple voltages can be applied and selected within the interval. This helped significantly in limiting the deviations, but it also increased the computation regime. Other studies were devoted to present some forms of cost functions which are free of weighting factors, and this was accomplished through selecting the function's terms of same type [40-42]. However, better dynamics were obtained, and the system became much simpler, but the used cost functions were very sensitive to the model's uncertainties.

To enhance the reliability of the IM drive, several studies were concerned with designing sensorless and observation mechanisms for estimating the rotational speed and other state variables [43-46]. In these studies, different forms of estimators were used such as least squared error, Kalman filters, extended Luenberger observer and neural-fuzzy estimator. The system's complexity was the main challenge in these schemes due to the expanded formulation of each observer with respect to the overall system. The MRAS observers were also introduced as a solution as in $[47,48]$, but they were very sensitive to parameter changes, specifically at low speeds. Position and speed estimation using high frequency injection (HFI) mechanisms are also introduced in $[49,50]$. The main idea of the HFI estimators depended on extracting the synchronous speed from the harmonics of stator currents using low and bass band filters. The main deficiency of this technique was the appropriate tuning of such filters to be valid for all operating speeds.

As a way to overcome the gaps in the well-known PTC and maintain the robustness of the system, the current study introduces a new predictive voltage control (PVC) which exploits a cost-function form of unique parts. The function's terms are the deviations of actual stator voltages from their references. The command voltages are obtained using the back-stepping theory. The back-stepping theory has been extensively used for both controlling and estimating the states of nonlinear systems [51,52]. This control theory was first presented by Kokotovic in the 1990s [53,54] and it was mainly concerned with designing stabilized controls for specified non-linear dynamic systems. This control algorithm enables a proper dynamic and steady state operation under the presence of system's uncertainties [45-57]. In [58], an adaptive back-stepping controller was applied for controlling the operation of an IM drive under external disturbances. In [59], an adaptive back-stepping controller was considered to achieve precise speed tracking despite the load torque changes and rotor resistance variation as well. In [60], an adaptive and robust back-stepping algorithm was utilized for optimizing the efficiency of an IM under system's uncertainties.

Thus, to exploit the advantages of back-stepping theory and its ability to handle the nonlinearities, the theory is utilized to generate the reference $d-q$ voltage terms which are used by the cost function of the designed PVC. In addition, in order to further simplify the overall control topology, the finite set control (FSC) principle is adopted to maintain the voltages selection within a determined number of voltages (eight voltages: two null and six active). This helped significantly in getting rid of traditional modulation schemes commonly used in vector and continuous predictive control schemes.

Furthermore, to avoid the complexity of the presented sensorless schemes mentioned earlier, and to ensure the proper and precise state observation at the same time, the paper introduces a robust Luenberger-sliding mode observer (L-SMO). The designed L-SMO is 
simple in terms of construction and at the same time provides an accurate observation for the speed, rotor flux, stator currents, and stator resistance as well. The validity of the observer is checked under load torque changes, stator resistance changes and for different operating speeds as well. The performance tests are carried out for the two control schemes, classic PTC and designed PVC, and a detailed analysis is presented through which the points of strength and weakness can be easily identified.

The paper introduces the following contributions to the literature:

- The study presents a new PVC scheme for a sensorless IM drive with the advantages of robustness, ripples reduction, simple construction, and faster dynamics.

- The design of the PVC is accomplished in sequence steps clarifying the base principle upon which each stage depends on.

- To enhance the system's robustness and reliability, a Luenberger-sliding mode (L$\mathrm{SMO}$ ) estimator is designed to observe the speed, stator currents, stator resistance and rotor flux as well.

- $\quad$ The IM performance is tested with the designed PVC and L-SMO under external load changes and parameters variation as well.

- $\quad$ A detailed comparative study between the classic PTC and proposed PVC considering the sensorless operation is accomplished, which clarifies the superiority of PVC over the well-known PTC.

- The designed PVC scheme can be utilized with different machine drives after considering the principle of operation and physical model of each type.

Section 2 presents model of the IM. In Section 3, the design of the PVC control is accomplished. Afterwards, Section 4 introduces the L-SMO observer's design. In Section 5, the test results are presented for the two control approaches (PTC and PVC). Finally, Section 6 introduces the summarized conclusions from the presented study.

\section{Modeling of IM}

The model of IM is presented through Figure 1. In this schematic, all machine variables are represented in the rotor flux rotating frame which rotates with a frequency of $\omega_{\bar{\psi}_{r}}$.

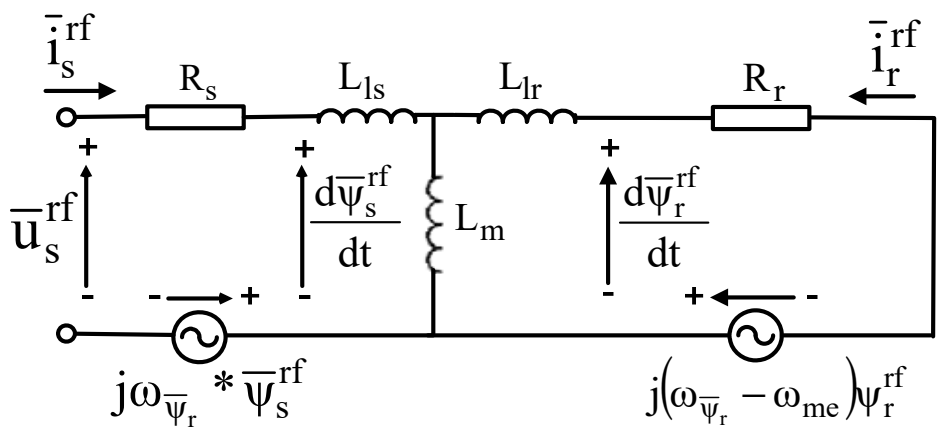

Figure 1. Modeling of IM in the synchronous rotating frame.

In Figure $1, R_{r}$ and $R_{s}$ represent the resistances of rotor and stator windings. Meanwhile, $L_{l s}$ and $L_{l r}$ represent the windings leakage inductance. $L_{m}$ represent the mutual inductance. The electrical rotor speed is expressed by $\omega_{m e}=p \omega_{m}$, where $\omega_{m}$ is the shaft speed. The notation ' $f$ ' states that all quantities are expressed in the rotor flux plane. The voltages, currents and fluxes of stator are defined by $\bar{u}_{s}^{r f}, \bar{l}_{s}^{r f}$ and $\bar{\psi}_{s}^{r f}$, respectively. Finally, the current and flux vectors of the rotor are expressed by $\iota_{r}^{r f}$ and $\bar{\psi}_{r}^{r f}$, in turn.

Then, from Figure 1, the dynamic model of IM can be expressed at instant $k T_{s}$ by

$$
\frac{d i_{d s, k}^{r f}}{d t}=\beta u_{d s, k}^{r f}-\gamma i_{d s, k}^{r f}+\omega_{\bar{\psi}_{r}} i_{q s, k}^{r f}+K \alpha_{r} \psi_{d r, k}^{r f}+K \omega_{m e, k} \psi_{q r, k}^{r f}
$$




$$
\begin{gathered}
\frac{d i_{q s, k}^{r f}}{d t}=\beta u_{q s, k}^{r f}-\gamma i_{q s, k}^{r f}-\omega_{\bar{\psi}_{r}} i_{d s, k}^{r f}+K \alpha_{r} \psi_{q r, k}^{r f}-K \omega_{m e, k} \psi_{d r, k}^{r f} \\
\frac{d \psi_{d r, k}^{r f}}{d t}=L_{m} \alpha_{r} i_{d s, k}^{r f}-\alpha_{r} \psi_{d r, k}^{r f}+\overbrace{\left(\omega_{\bar{\psi}_{r}}-\omega_{m e, k}\right)}^{\omega_{s l, k}} \psi_{q r, k}^{r f} \\
\frac{d \psi_{q r, k}^{r f}}{d t}=L_{m} \alpha_{r} i_{q s, k}^{r f}-\alpha_{r} \psi_{q r, k}^{r f}-\omega_{s l, k} \psi_{d r, k}^{r f} \\
\frac{d \omega_{m e, k}}{d t}=\frac{p}{J}\left(T_{e, k}-T_{l, k}\right)
\end{gathered}
$$

where $\beta=\frac{1}{\sigma L_{s}}, \gamma=\beta R_{\gamma}, R_{\gamma}=R_{s}+\frac{L_{m}^{2}}{L_{r}^{2}} R_{r}, \sigma=1-\frac{L_{m}^{2}}{L_{s} L_{r}}, K=\beta \frac{L_{m}}{L_{r}}, \alpha_{r}=\frac{L_{r}}{R_{r}}=\frac{1}{T_{r}}$.

Assuming a perfect orientation $\left(\psi_{d r, k}^{r f}=\bar{\psi}_{r, k}^{r f}\right.$ and $\left.\psi_{q r, k}^{r f}=0.0\right)$, then the relationships (1)-(5) can be represented by

$$
\begin{gathered}
\frac{d \omega_{m e, k}}{d t}=f_{1, k} \\
\frac{d \psi_{d r, k}^{r f}}{d t}=f_{2, k} \\
\frac{d i_{d s, k}^{r f}}{d t}=f_{3, k}+\beta u_{d s, k}^{r f} \\
\frac{d i_{q s, k}^{r f}}{d t}=f_{4, k}+\beta u_{q s, k}^{r f} \\
\frac{d \theta_{s, k}^{r f}}{d t}=\omega_{m e, k}+\omega_{s l, k}
\end{gathered}
$$

where $\omega_{s l, k}=L_{m} \alpha_{r} \frac{i_{q s, k}^{r f}}{\psi_{d r, k}^{r f}}$ and

$$
\begin{gathered}
f_{1, k}=1.5 \frac{p^{2} L_{m}}{J L_{r}} \psi_{d r, k}^{r f} i_{q s, k}^{r f}-\frac{p}{J} T_{l, k} \\
f_{2, k}=L_{m} \alpha_{r} i_{d s, k}^{r f}-\alpha_{r} \psi_{d r, k}^{r f} \\
f_{3, k}=-\gamma i_{d s, k}^{r f}+\omega_{m e, k} i_{q s, k}^{r f}+L_{m} \alpha_{r} \frac{i_{q s, k}^{2}}{\psi_{d r, k}^{r f}}+K \alpha_{r} \psi_{d r, k}^{r f} \\
f_{4, k}=-\gamma i_{q s, k}^{r f}-\omega_{m e, k} i_{d s, k}^{r f}-L_{m} \alpha_{r} \frac{i_{d s, k}^{r f} i_{q s, k}^{r f}}{\psi_{d r, k}^{r f}}-K \omega_{m e, k} \psi_{d r, k}^{r f}
\end{gathered}
$$

The developed torque $T_{e, k}$ is calculated by

$$
T_{e, k}=1.5 p \frac{L_{m}}{\sigma L_{s} L_{r}} \bar{\psi}_{s, k}^{r f} \times \bar{\psi}_{r, k}^{r f}
$$

where $\times$ refers to the cross product of the two flux vectors. The flux vectors in (8) can be formulated in exponential representations by

$$
\bar{\psi}_{s, k}^{r f}=\left|\bar{\psi}_{s, k}^{r f}\right| e^{j \omega_{\bar{\psi}_{s, k}}{ }^{2}, \text { and } \bar{\psi}_{r, k}^{r f}}=\left|\bar{\psi}_{r, k}^{r f}\right| e^{j \omega_{\bar{\psi}_{r, k}} t}
$$

where $\omega_{\bar{\psi}_{s, k}}$ and $\omega_{\bar{\psi}_{r, k}}$ are the stator and rotor fluxes rotating speeds. 
The main idea of the paper is to find a direct relationship between the torque current component $\left(i_{q s, k}^{r f}\right)$ and flux current component $\left(i_{d s, k}^{r f}\right)$ and the voltage components $u_{q s, k}^{r f}$ and $u_{d s, k^{\prime}}^{r f}$, respectively. The reference voltage components are obtained using a back-stepping controller. Then, they are used in a designed cost function which combines the absolute errors between the actual and reference voltages. Therefore, the designed cost function does not require a weighting factor and also does not utilize any estimated quantities similar to that used in the predictive torque and flux control schemes. The selection of voltages via the minimization of cost function value is performed using the finite control set mechanism which enables the selection between a definite set of voltages (eight vectors), which enables the elimination of PWM and consequently simplifies the overall control structure and limit the commutation losses.

\section{Generation of Voltages Using Backstepping Regulator}

The basic principle of the back-stepping control design is the utilization of the so-called "virtual control" to regularly divide a complex nonlinear-control problem into smaller and simpler ones. Back-stepping control design is decomposed into different design stages. Each stage handles a single input-single-output (SISO) design issue, and each design stage develops a reference for the next stage. The general performance and stability are ensured using Lyapunov theory for the complete system. The organization of this control topology can be performed through two subsequent stages.

\subsection{Stage 1: Generation of Reference Currents}

In the first stage, it is mandatory that the system follows a presented trajectory for each output variable. To ensure this, a criterion $y_{c, k}=\left(\psi_{c, k}, \omega_{c, k}\right)$ is considered, where $\psi_{c, k}$ and $\omega_{c, k}$ are the reference quantities of rotor flux and speed, respectively. The flux and speed tracking errors $e_{\psi}$ and $e_{\omega}$ are then expressed by:

$$
\begin{gathered}
e_{\psi, k}=\psi_{c, k}-\psi_{d r, k}^{r f} \\
e_{\omega, k}=\omega_{c, k}-\omega_{m e, k}
\end{gathered}
$$

The differentials of (10) can be expressed by

$$
\begin{gathered}
\dot{e}_{\psi, k}=\dot{\psi}_{c, k}-\dot{\psi}_{d r, k}^{r f} \\
\dot{e}_{\omega, k}=\dot{\omega}_{c, k}-\dot{\omega}_{m e, k}
\end{gathered}
$$

Using (7), the relationships of (11) can be represented by

$$
\begin{aligned}
& \dot{e}_{\psi, k}=\dot{\psi}_{c, k}-f_{2, k} \\
& \dot{e}_{\omega, k}=\dot{\omega}_{c, k}-f_{1, k}
\end{aligned}
$$

To check, let the tracking performances select the first Lyapunov candidate $v_{1, k}$ related to the speed and rotor flux deviations, so that

$$
v_{1, k}=\frac{e_{\psi, k}^{2}+e_{\omega, k}^{2}}{2}
$$

Utilizing (12), the derivation of (13) results in

$$
\dot{v}_{1, k}=e_{\psi, k}\left(\dot{\psi}_{c, k}-f_{2, k}\right)+e_{\omega, k}\left(\dot{\omega}_{c, k}-f_{1, k}\right)
$$

This can be reformulated by

$$
\dot{v}_{1, k}=-k_{1} e_{\psi, k}^{2}-k_{2} e_{\omega, k}^{2}
$$


where $k_{1}$ and $k_{2}$ must be positive constants to ensure a stable reference tracking. This result in

$$
\begin{gathered}
\dot{e}_{\psi, k}=\dot{\psi}_{c, k}-\dot{\psi}_{d r, k}^{r f}=-k_{1} e_{\psi, k} \\
\dot{e}_{\omega, k}=\dot{\omega}_{c, k}-\dot{\omega}_{m e, k}=-k_{2} e_{\omega, k}
\end{gathered}
$$

where

$$
\begin{gathered}
\dot{\psi}_{d r, k}^{r f}=\dot{\psi}_{c, k}+k_{1} e_{\psi, k} \\
\dot{\omega}_{m e, k}=\dot{\omega}_{c, k}+k_{2} e_{\omega, k}
\end{gathered}
$$

The relationships in (17) enable the determination of current references as following

$$
\begin{gathered}
\left(i_{d s, k}^{r f}\right)_{c}=\frac{1}{L_{m} \alpha_{r}}\left(\dot{\psi}_{c, k}+\alpha_{r} \psi_{d r, k}^{r f}+k_{1} e_{\psi, k}\right) \\
\left(i_{q s, k}^{r f}\right)_{c}=\frac{1}{\left(\frac{1.5 L_{m} p^{2}}{J L_{r}}\right) \psi_{d r, k}^{r f}}\left(\dot{\omega}_{c, k}+\frac{p}{J} T_{l, k}+k_{2} e_{\omega, k}\right)
\end{gathered}
$$

3.2. Stage 2: Calculation of Reference Voltages $\left(u_{d s, k}^{*}\right.$ and $u_{q s, k}^{*}$ )

This stage is concerned with generating the reference $d$ - $q$ voltages $u_{d s, k}^{*}, u_{q s, k}^{*}$ which will be used later by the designed cost function of the predictive controller.

The current deviations are expressed by

$$
\begin{aligned}
& e_{i_{d}}=\left(i_{d s, k}^{r f}\right)_{c}-i_{d s, k}^{r f} \\
& e_{i_{q}}=\left(i_{q s, k}^{r f}\right)_{c}-i_{q s, k}^{r f}
\end{aligned}
$$

By substituting from (18) into (19), it results

$$
\begin{gathered}
e_{i_{d}}=\frac{1}{L_{m} \alpha_{r}}\left(\dot{\psi}_{c, k}+\alpha_{r} \psi_{d r, k}^{r f}+k_{1} e_{\psi, k}\right)-i_{d s, k}^{r f} \\
e_{i_{q}}=\frac{1}{\left(\frac{1.5 L_{m} p^{2}}{L_{r}}\right) \psi_{d r, k}^{r f}}\left(\dot{\omega}_{c, k}+\frac{p}{J} T_{l, k}+k_{2} e_{\omega, k}\right)-i_{q s, k}^{r f}
\end{gathered}
$$

Taking the derivative of (19), it yields

$$
\begin{aligned}
& \dot{e}_{i_{d}}=\left(i_{d s, k}^{r f}\right)_{c}-i_{d s, k}^{r f} \\
& \dot{e}_{i_{q}}=\left(i_{q s, k}^{r f}\right)_{c}-i_{q s, k}^{r f}
\end{aligned}
$$

From (7) and by replacing into (21), this results in

$$
\begin{aligned}
& \dot{e}_{i_{d}}=\left(i_{d s, k}^{r f}\right)_{c}-i_{d s, k}^{r f}=\left(i_{d s, k}^{r f}\right)_{c}-f_{3, k}-\beta u_{d s, k}^{r f} \\
& \dot{e}_{i_{q}}=\left(i_{q s, k}^{r f}\right)_{c}-i_{q s, k}^{r f}=\left(i_{q s, k}^{r f}\right)_{c}-f_{4, k}-\beta u_{q s, k}^{r f}
\end{aligned}
$$

The relationships in (22) contain the system's inputs (stator voltages). Then, a new Lyapunov candidate can be defined using the deviations of stator currents, rotor flux, and speed as follows

$$
v_{2, k}=\frac{e_{i_{d, k}}^{2}+e_{i_{q, k}}^{2}+e_{\psi, k}^{2}+e_{\omega, k}^{2}}{2}
$$


The derivative of (23) can be defined by

$$
\dot{v}_{2, k}=e_{i_{d, k}} \dot{e}_{i_{d, k}}+e_{i_{q, k}} \dot{e}_{i_{q, k}}+e_{\psi, k} \dot{e}_{\psi, k}+e_{\omega, k} \dot{e}_{\omega, k}
$$

By substituting from (19) into (24), it gives

$$
\begin{gathered}
\dot{v}_{2, k}=-k_{3} e_{i_{d}}^{2}-k_{4} e_{i_{q}}^{2}-k_{1} e_{\psi, k}^{2}-k_{2} e_{\omega, k}^{2}+e_{i_{d}}\left(k_{3} e_{i_{d}}+\left(i_{q s, k}^{r f}\right)_{c}-f_{4, k}-\beta u_{q s, k}^{r f}\right) \\
+e_{i_{q}}\left(k_{4} e_{i_{q}}+\left(i_{d s, k}^{r f}\right)_{c}-f_{3, k}-\beta u_{d s, k}^{r f}\right)
\end{gathered}
$$

The derivative of the Lyapunov candidate of (25) can be with negative definite state if the summations between the brackets are zero, then

$$
\begin{aligned}
& k_{3} e_{i_{d}}+\left(i_{q s, k}^{r f}\right)_{c}-f_{4, k}-\beta u_{q s, k}^{r f}=0.0 \\
& k_{4} e_{i_{q}}+\left(i_{d s, k}^{r f}\right)_{c}-f_{3, k}-\beta u_{d s, k}^{r f}=0.0
\end{aligned}
$$

where $k_{3}$ and $k_{4}$ are positive values identified to ensure the fast dynamic of stator current components, which in turn are responsible for the flux and speed variation.

Then, from (26), the reference voltages can be derived as following

$$
\begin{aligned}
& u_{d s, k}^{*}=\left(k_{4} e_{i_{q}}+\left(i_{d s, k}^{r f}\right)_{c}-f_{3, k}\right) / \beta \\
& u_{q s, k}^{*}=\left(k_{3} e_{i_{d}}+\left(i_{q s, k}^{r f}\right)_{c}-f_{4, k}\right) / \beta
\end{aligned}
$$

The overall schematic diagram of the designed back-stepping observer can be illustrated now in Figure 2, which summarizes all the mathematical relationships.

After obtaining the reference voltages $u_{d s, k}^{*}$ and $u_{q s, k}^{*}$, they are also obtained at instant $(k+1) T_{s}$ via substituting the predicted values of current, flux and speed starting from the relationships (1)-(5). After that the reference voltages $u_{d s, k+1}^{*}$ and $u_{q s, k+1}^{*}$ can be utilized in the following designed cost function

$$
\widetilde{\zeta}_{k+1}^{i}=\left|u_{d s, k+1}^{*}-u_{d s, k+1}\right|^{i}+\left|u_{q s, k+1}^{*}-u_{q s, k+1}\right|^{i}
$$

In (28), it is observed that the used function form by the proposed PVC approach is less sensitive and more simple compared with the cost functions used by several PTC approaches [61,62], and which is represented by

$$
\Delta_{k+1}^{i}=\left|T_{e, k+1}^{*}-\widetilde{T}_{e, k+1}\right|^{i}+w_{f}\left|\psi_{s, k+1}^{*}-\widetilde{\bar{\psi}}_{s, k+1}\right|^{i}
$$

By checking (28) and comparing it with (29), it is very clear that the designed cost function is more compact as it does not depend on estimated variables like (29). Moreover, the function (28) provides a faster dynamic response because it deals with the applied voltages variation. In addition, the designed PVC results in lower switching actions as the time taken to evaluate the cost function is much lower than the time taken to evaluate (29). 


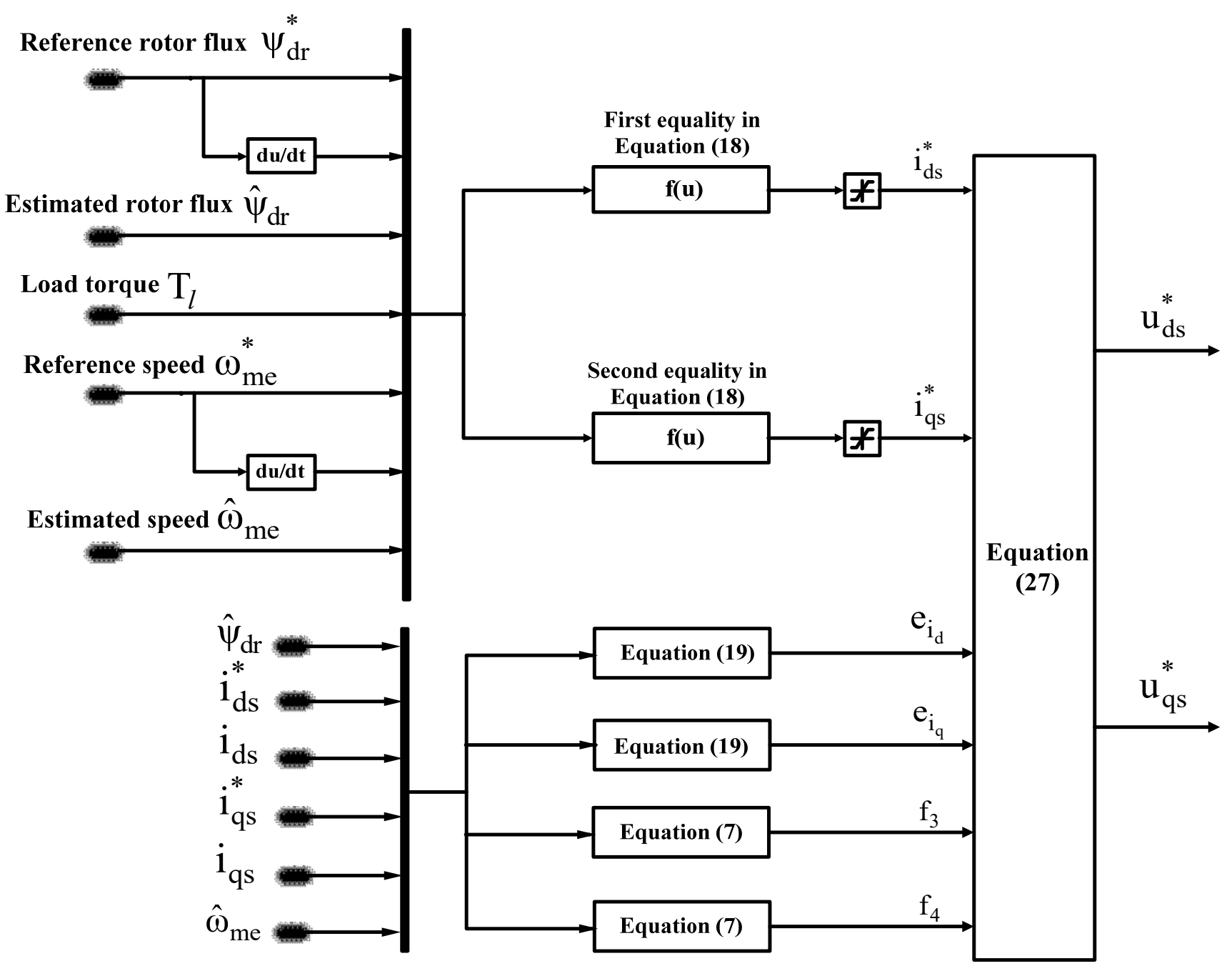

Figure 2. Layout of internal structure of backstepping controller.

\section{Proposed Luenberger-Sliding Mode Observer}

Compared with the observers used in the literature work, the proposed observer is very simple in its construction, which significantly reduces the computational burden during the estimation. The observer is a closed loop which feeds the observed variables back for error correction and minimization. The Luenberger part of the observer is designed based on the machine model, while the sliding mode part deals with the measurements noise and parameters mismatch. The two combined parts help in achieving fast and precise tracking of the estimated variables.

Based on the IM model, the state representations can be expressed as follows

$$
\begin{gathered}
\dot{\bar{x}}_{k}=A \bar{x}_{k}+B \bar{u}_{s, k} \\
\bar{\iota}_{s, k}=C \bar{x}_{k}
\end{gathered}
$$

where $\bar{x}_{k}=\left[\begin{array}{ll}\bar{\iota}_{s, k} & \bar{\psi}_{r, k}\end{array}\right]^{T}, B=\left[\begin{array}{ll}I / \sigma L_{s} & 0\end{array}\right]^{T}, C=\left[\begin{array}{ll}I & 0\end{array}\right] \bar{\iota}_{s, k}=\left[\begin{array}{ll}i_{d s, k} & i_{q s, k}\end{array}\right]^{T}$, $\bar{\psi}_{r, k}=\left[\begin{array}{ll}\psi_{d r, k} & \psi_{q r, k}\end{array}\right]^{T}$

$$
A=\left[\begin{array}{cc}
\frac{-1}{\sigma}\left(\frac{1}{\tau_{s}}+\frac{1-\sigma}{T_{r}}\right) I & \frac{L_{m}}{\sigma L_{s} L_{r}}\left(\frac{I}{T_{r}}-\omega_{m e} M\right) \\
\frac{L_{m} I}{T_{r}} & -\frac{I}{T_{r}}+\omega_{m e} M
\end{array}\right] I=\left[\begin{array}{cc}
1 & 0 \\
0 & 1
\end{array}\right] \text { and } M=\left[\begin{array}{cc}
0 & -1 \\
1 & 0
\end{array}\right]
$$

where $\tau_{S}=L_{S} / R_{S}$ is the stator time constant. 
The mechanism by which the Luenberger-sliding mode observer (L-SMO) simultaneously estimates the stator current and rotor flux can be described by

$$
\begin{gathered}
\dot{\hat{x}}_{k}=\hat{A} \hat{x}_{k}+B \bar{u}_{s, k}+\left[L \widetilde{\imath}_{s, k}+\operatorname{Ksgn}\left(\widetilde{\imath}_{s, k}\right)\right] \\
\hat{\iota}_{s, k}=C \hat{x}_{k}
\end{gathered}
$$

where $\widetilde{\iota}_{s, k}=\bar{\iota}_{s, k}-\hat{\iota}_{s, k}$ is the current error, and accent ${ }^{\wedge}$ refers to the estimated value.

The sliding mode component of the estimator in (32) is represented by $\operatorname{Ksgn}\left(\widetilde{\iota}_{\mathrm{s}, \mathrm{k}}\right)$, while the Luenberger estimator component is represented by $L \widetilde{s}_{\mathrm{s}, \mathrm{k}}$. Moreover, $K$ and $L$ are the matrices of the observer gains. Figure 3 illustrates the proposed L-SMO for the IM drive.

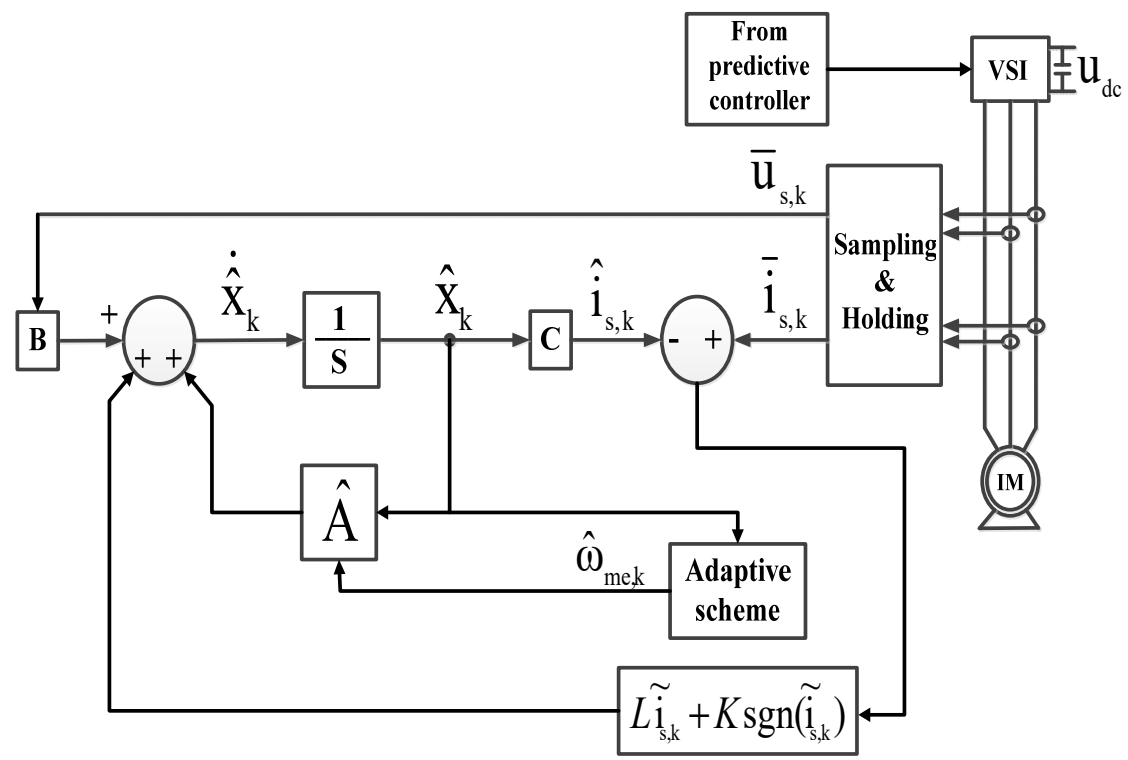

Figure 3. Proposed L-SMO observer system for IM drive.

As shown, the Luenberger component is concerned with estimating the stator current, the rotor flux and rotor speed. Meanwhile, the sliding mode term is used to ensure the system's robustness against any disturbance.

The matrices $K$ and $L$ are designed so that $\hat{x}_{k}-x_{k} \rightarrow 0.0$ and $\bar{l}_{s, k}-\hat{\imath}_{s, k} \rightarrow 0.0$ with a time limit $t \rightarrow \infty$.

Identifying the coefficients of gain matrix $K$ is performed via comparing the characteristic equation of the observer with the one we wish to impose. In developing the different matrices $A, C$, and $K$, we obtain the following equation:

$$
p^{2}+\left(\frac{1}{\sigma \tau_{s}}+\frac{1}{\sigma T_{r}}-j \hat{\omega}_{m e}+K^{\prime}\right) p+\left(\frac{1}{T_{r}}-j \hat{\omega}_{m e}\right)\left\{\left(\frac{1}{\sigma \tau_{s}}+\frac{1}{\sigma T_{r}}\right)+K^{\prime}\right\}+\left(\frac{L_{m}}{T_{r}}-K^{\prime \prime}\right)\left(\frac{L_{m}}{\sigma L_{s} L_{r}}\right)\left(\frac{1}{T_{r}}-j \hat{\omega}_{m e}\right)=0.0
$$

where $K^{\prime}$ and $K^{\prime \prime}$ are complex gains. And $p$ is the differential operator.

Furthermore, the observer's dynamics can be also defined using the following equation:

$$
p^{2}+k\left(\frac{1}{\sigma \tau_{s}}+\frac{1}{\sigma T_{r}}-j \hat{\omega}_{m e}\right) p+k^{2}\left(\frac{1}{T_{r}}-j \hat{\omega}_{m e}\right)\left(\frac{1}{\sigma \tau_{s}}+\frac{1}{\sigma T_{r}}\right)+\left(\frac{L_{m}}{T_{r}}\right)\left(\frac{L_{m}}{\sigma L_{s} L_{r}}\right)\left(\frac{1}{T_{r}}-j \hat{\omega}_{m e}\right)=0.0
$$

The roots of (35) are proportional to the motor's model poles. The proportionality coefficient $k$ is then moved within a range of $0<k<1$.

Thus, using (34) and (35), the following is obtained

$$
K^{\prime}=(k-1)\left(\frac{1}{\sigma \tau_{s}}+\frac{1}{\sigma T_{r}}-j \hat{\omega}_{m e}\right)
$$




$$
K^{\prime \prime}=(k-1)\left[\left\{\left(\frac{1}{\sigma \tau_{s}}+\frac{1}{\sigma T_{r}}\right) \frac{\sigma L_{s} L_{m}}{L_{r}}-\frac{L_{m}}{T_{r}}\right\}(k-1)-\frac{\sigma L_{s} L_{m}}{L_{r}}\left(\frac{1}{\sigma \tau_{s}}+\frac{1}{\sigma T_{r}}\right)+j \hat{\omega}_{m e} \frac{\sigma L_{s} L_{m}}{L_{r}}\right]
$$

The gain matrix coefficients of the observer are then evaluated by

$$
\begin{aligned}
& K^{\prime}=K_{1}+j K_{2} \\
& K^{\prime \prime}=K_{3}+j K_{4}
\end{aligned}
$$

Following the anti-symmetry of the matrix $A$, the gain matrix $K$ is set as following

$$
K=\left[\begin{array}{cc}
K_{1} & -K_{2} \\
K_{2} & K_{1} \\
K_{3} & -K_{4} \\
K_{4} & K_{3}
\end{array}\right]
$$

where

$$
\begin{gathered}
K_{1}=(k-1)\left(\frac{1}{\sigma \tau_{s}}+\frac{(1-\sigma)}{\sigma T_{r}}+\frac{1}{T_{r}}\right) \\
K_{2}=(k-1) \hat{\omega}_{m e} \\
K_{3}=-\sigma L_{s} L_{r} \frac{\left(1-k^{2}\right)}{L_{m}}\left(\frac{1}{\sigma L_{s}}+\frac{(1-\sigma)}{\sigma T_{r}}-\frac{L_{m}}{\sigma L_{s} L_{r} T_{r}}\right)-\sigma L_{s} L_{r} \frac{(k-1)}{L_{m}}\left(\frac{1}{\sigma \tau_{s}}+\frac{(1-\sigma)}{\sigma T_{r}}+\frac{1}{T_{r}}\right) \\
K_{4}=-\sigma L_{s} L_{r} \frac{(k-1)}{L_{m}} \hat{\omega}_{m e}
\end{gathered}
$$

The observer's poles are selected to accelerate convergence to the dynamics of the open loop system. Generally, the poles are 5-6 times faster, but they must remain slow in relevant to the measurement noise, so that the constant $k$ is usually selected small.

The dynamics of the output error from the estimator can be obtained by subtracting (32) from (30), then

$$
\frac{d}{d t}(e)=\frac{d}{d t}\left(C \bar{x}_{k}-C \hat{x}_{k}\right)=C(A-L C) C^{T} e-C \Delta A \hat{x}_{k}-C \operatorname{Ksgn}(e)
$$

where $\Delta A=\hat{A}-A$ The next step is to analyze the dynamics of the output error, and for this purpose the Lyapunov's stability check is utilized. A Lyapunov's relationship is presented to obtain an expression for the rotor speed estimation as follows,

$$
V=e^{T} e+\frac{\left(\hat{\omega}_{m e, k}-\omega_{m e, k}\right)^{2}}{a}
$$

where ' $a$ ' is a positive value. Then, the derivative of $V$ is

$$
\begin{gathered}
\frac{d V}{d t}=\left[e^{T}\left[\left\{C(A-L C) C^{T}\right\}^{T}+\left\{C(A-L C) C^{T}\right\}\right] e-K^{T} C^{T} \operatorname{esgn}(e)-e^{T} C \operatorname{Ksgn}(e)\right]+\frac{2 L_{m}\left(\hat{\omega}_{m e, k}-\omega_{m e, k}\right)}{\left(L_{s} L_{r}-L_{m}^{2}\right)} \\
*\left\{\hat{\psi}_{q r, k}\left(i_{d s, k}-\hat{\imath}_{d s, k}\right)-\hat{\psi}_{d r, k}\left(i_{q s, k}-\hat{\imath}_{q s, k}\right)\right\}+\frac{2\left(\hat{\omega}_{m e, k}-\omega_{m e, k}\right)}{a} \frac{d \hat{\omega}_{m e, k}}{d t}
\end{gathered}
$$

The convergence is achieved when $V$ decreases each time happens that the error deviates from zero, which means that the derivation of Lyapunov's criterion is negative. As the first part of (41) is continually negative, then the condition is fulfilled when the summation of the last two parts is zero. Thus, the relationship used for identifying the rotor speed is expressed by

$$
\frac{d \hat{\omega}_{m e, k}}{d t}=K_{v} *\left\{\hat{\psi}_{q r, k}\left(i_{d s, k}-\hat{\imath}_{d s, k}\right)-\hat{\psi}_{d r, k}\left(i_{q s, k}-\hat{\imath}_{q s, k}\right)\right\}
$$

where $K_{v}=\frac{a L_{m}}{\sigma L_{s} L_{r}}$. 
To ensure the correct field orientation, the angular slip frequency $\hat{\omega}_{\text {slip, } k}$ must be appropriately estimated utilizing the estimated flux and rotor time constant. An expression for the Luapunov's relationship is used for the rotor time constant $\tau_{r}$ estimation as follows

$$
V=e^{T} e+\frac{\left(\hat{\tau}_{r, k}-\tau_{r, k}\right)^{2}}{a}
$$

where $\hat{\tau}_{r, k}$ is the observed time constant at instant $k T_{s}$.

As a result, the derivative of (44) yields

$$
\begin{aligned}
\frac{d V}{d t}=\left[e^{T}\left[\left\{C(A-L C) C^{T}\right\}^{T}+\left\{C(A-L C) C^{T}\right\}\right] e-K^{T} C^{T} \operatorname{esgn}(e)-e^{T} C K s g n(e)\right]+\frac{2 L_{m}\left(\hat{\tau}_{r, k}-\tau_{r, k}\right)}{\left(L_{s} L_{r}-L_{m}^{2}\right)} \\
\\
*\left\{\left(\hat{\psi}_{d r, k}-L_{m} \hat{\imath}_{d s, k}\right)\left(i_{d s, k}-\hat{\imath}_{d s, k}\right)+\left(\hat{\psi}_{q r, k}-L_{m} \hat{\imath}_{q s, k}\right)\left(\hat{\imath}_{q s, k}-\hat{\imath}_{q s, k}\right)\right\}+\frac{2\left(\hat{\tau}_{r, k}-\tau_{r, k}\right)}{a} \frac{d \hat{t}_{r, k}}{d t}
\end{aligned}
$$

The convergence is achieved when the candidate $V$ decreases each time happens that the error diverges from zero, which results in a negative derivative of Lyapunov's criterion. As the first part of (44) is negative, to achieve the condition, the summation of the last two parts in (45) must equal zero. Thus, the identifier of $\hat{\tau}_{r, k}$ can be expressed by

$$
\frac{d \hat{\tau}_{r, k}}{d t}=K_{r} L_{r}\left\{\left(\hat{\psi}_{d r, k}-L_{m} \hat{\iota}_{d s, k}\right)\left(i_{d s, k}-\hat{\iota}_{d s, k}\right)+\left(\hat{\psi}_{q r, k}-L_{m} \hat{\iota}_{g s, k}\right)\left(\hat{\iota}_{q s, k}-\hat{\iota}_{q s, k}\right)\right\}
$$

where $K_{r}=\frac{L_{m} a}{\left(L_{s} L_{r}-L_{m}^{2}\right)}$. And ' $a$ ' is a positive definite.

In the same way, an expression for the Lyapunov's relationship is used for the stator resistance $R_{S}$ estimation as follows

$$
V=e^{T} e+\frac{\left(\hat{R}_{s, k}-R_{s, k}\right)^{2}}{a}
$$

where $\hat{R}_{s, k}$ is the observed stator resistance at instant $k T_{s}$.

As a result, the derivative of (47) yields

$$
\begin{aligned}
\frac{d V}{d t}=\left[e^{T}\left[\left\{C(A-L C) C^{T}\right\}^{T}+\left\{C(A-L C) C^{T}\right\}\right] e-K^{T} C^{T} \operatorname{esgn}(e)-e^{T} C K \operatorname{sgn}(e)\right]+\frac{2 a\left(\hat{R}_{s, k}-R_{s, k}\right)}{\sigma L_{s}} \\
\\
*\left\{\hat{\imath}_{d s, k}\left(i_{d s, k}-\hat{\imath}_{d s, k}\right)+\hat{\imath}_{q s, k}\left(\hat{\imath}_{q s, k}-\hat{\imath}_{q s, k}\right)\right\}+\frac{2\left(\hat{R}_{s, k}-R_{s, k}\right)}{a} \frac{d \hat{R}_{s, k}}{d t}
\end{aligned}
$$

From (48), the convergence is achieved when the equivalent summation of the last two parts is zero, which results in the following expression

$$
\frac{d \hat{R}_{s, k}}{d t}=-K_{s}\left\{\hat{\imath}_{d s, k}\left(i_{d s, k}-\hat{\imath}_{d s, k}\right)+\hat{\imath}_{q s, k}\left(\hat{\imath}_{q s, k}-\hat{\imath}_{q s, k}\right)\right\}
$$

where $K_{s}=\frac{a}{\sigma L_{s}}$. Thus, via using (40), the stator resistance variation can be appropriately observed.

As can be noticed from the speed and consequently the stator resistance estimation, they obviously depend on the accuracy and stability of rotor flux estimation, and this is satisfied as follows:

The error's dynamic of rotor flux estimation can be defined by

$$
\begin{gathered}
\frac{d e_{\psi}}{d t}=\left(A_{22}+H A_{12}\right) e_{\psi} \\
\text { where } H=-x I-y M, x \geq-\varepsilon+\frac{\gamma}{\varepsilon \tau_{r}}, y \geq \frac{\gamma \omega_{m e}}{\varepsilon}
\end{gathered}
$$

where $\varepsilon=\frac{\sigma L_{L} L_{r}}{L_{m}}$, and $\gamma>0.0$ is a positive constant.

Assuming the speed is a known parameter, rotor flux estimation error can be represented by (50), with a matrix of the system equals to

$$
A_{\psi}=A_{22}+H A_{12}=-\alpha \pm \beta
$$




$$
\text { With }-\alpha=-c x-d y-\frac{1}{\tau_{r}} \text {, and } \beta=d x-c y+\omega_{m e}
$$

where $c=\frac{1}{\varepsilon \tau_{r}}, d=\frac{\omega_{m e}}{\varepsilon}$.

The eigenvalues of the closed-loop error system are given by

$$
\lambda_{1,2}=-\alpha \pm \beta
$$

The convergence conditions of the speed adaptation can be expressed as function of a positive design parameter $q \geq 0.0$ as follows

$$
x=(q-1) \varepsilon+\frac{\gamma}{\varepsilon \tau_{r}} \text { and } y=q \frac{\gamma \omega_{m e}}{\varepsilon}
$$

Now, by substituting from (55) into (53) and (54), the following is obtained

$$
\lambda_{1,2}=-q\left\{\left(\frac{1}{\tau_{r}}+\frac{\gamma}{q} \frac{1}{\tau_{r}^{2} \varepsilon^{2}}+\gamma \frac{\omega_{m e}^{2}}{\varepsilon^{2}}\right) \mp j\left[\omega_{m e}+\frac{\omega_{m e}}{\varepsilon^{2} \tau_{r}}\left(\frac{\gamma}{q}-1\right)\right]\right\}
$$

From (56), it is confirmed that the eigenvalues of rotor flux error's system are stable which is reflected on the convergence of the speed and stator resistance estimation. The main system parameters of such error system are $q$ and $\gamma$ which are chosen to enhance the flux estimation. The effect of these two parameters on the eigenvalues placement in the complex plane is presented in Figure 4, which reports that the selected values of parameters are sufficient to ensure the system's stability.
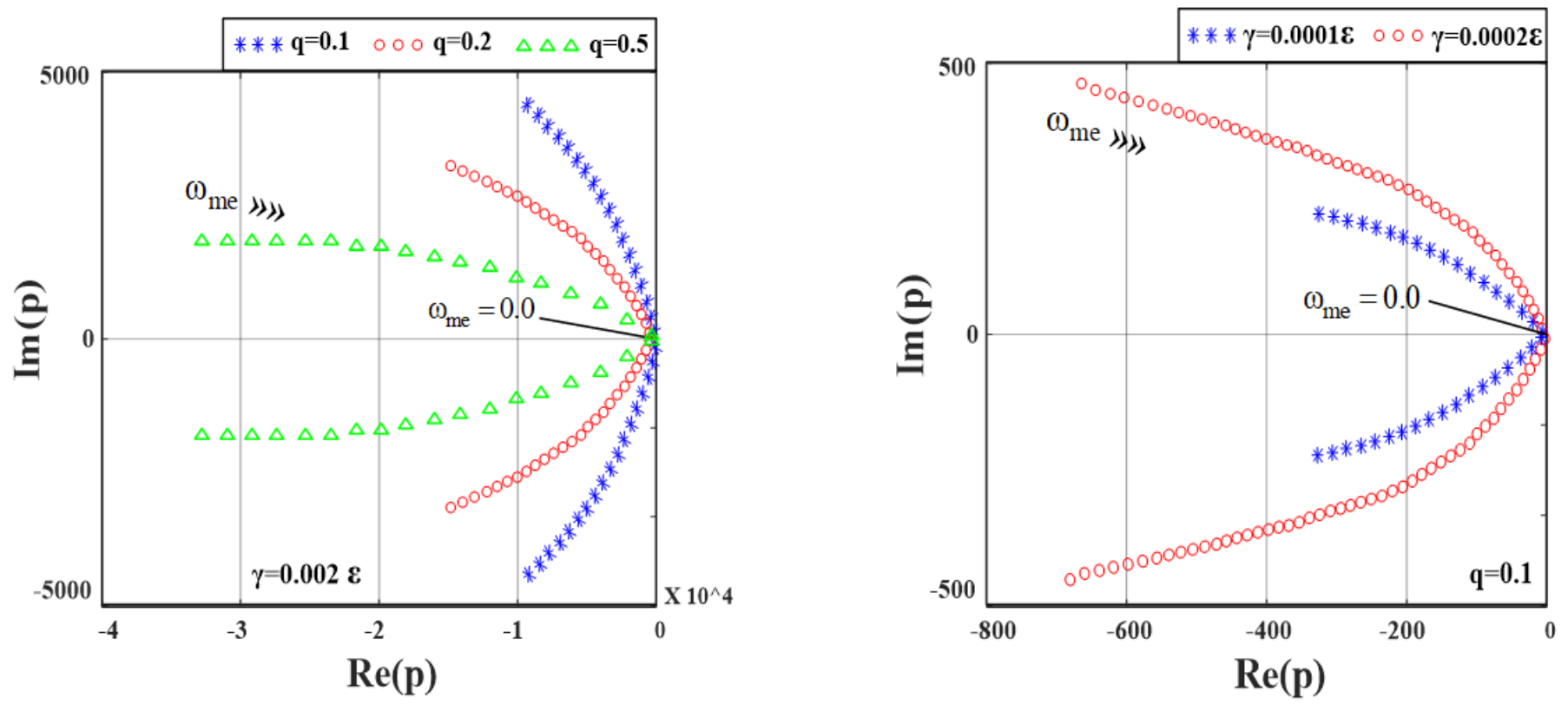

Figure 4. Eignenvalues of rotor flux estimation error's system.

As can be noticed from (49), the estimation formula of stator resistance is obtained through applying a Lyapunov's stability checking for the candidate $V$ in (47) which represents the error dynamics of the variable to be estimated. The convergence of resistance estimation can be also performed without the dependency on the error dynamics as follows.

The IM's dynamics can be described by the following expressions, which are represented in stator frame as

$$
\frac{d \bar{l}_{s, k}}{d t}=A_{11} \bar{\iota}_{s, k}+A_{12} \bar{\psi}_{r, k}+z \bar{u}_{s, k}
$$




$$
\frac{d \bar{\psi}_{r, k}}{d t}=A_{21} \bar{\iota}_{s, k}+A_{22} \bar{\psi}_{r, k}
$$

where $\bar{u}_{s, k}=\left[\begin{array}{ll}u_{d s, k} & u_{q s, k}\end{array}\right]^{T}, \bar{\psi}_{r, k}=\left[\begin{array}{ll}\psi_{d r, k} & \psi_{q r, k}\end{array}\right]^{T}, \bar{\iota}_{s, k}=\left[\begin{array}{ll}i_{d s, k} & i_{q s, k}\end{array}\right]^{T}$, and $z=\frac{1}{\sigma L_{s}}\left[\begin{array}{ll}1 & 0 \\ 0 & 1\end{array}\right]$.

The adaptive model can be constituted using (57) and (58) as follows

$$
\begin{gathered}
\frac{d \hat{\iota}_{s, k}}{d t}=\hat{A}_{11} \hat{\iota}_{s, k}+\hat{A}_{12} \hat{\psi}_{r, k}+z \bar{u}_{s, k}-K\left(\hat{\imath}_{s, k}-\bar{\iota}_{s, k}\right) \\
\frac{d \hat{\psi}_{r, k}}{d t}=\hat{A}_{21} \hat{\iota}_{s, k}+\hat{A}_{22} \hat{\psi}_{r, k}
\end{gathered}
$$

Subtracting (57)-(60), it results

$$
\begin{gathered}
\frac{d \bar{e}_{i, k}}{d t}=\left(A_{11}-K\right) \bar{e}_{i, k}+A_{12} \bar{e}_{\psi, k}+\Delta A_{12} \hat{\psi}_{r, k}+\Delta A_{11} \hat{\iota}_{s, k} \\
\frac{d \bar{e}_{\psi, k}}{d t}=A_{21} \bar{e}_{i, k}+A_{22} \bar{e}_{\psi, k}+\Delta A_{22} \hat{\psi}_{r, k}
\end{gathered}
$$

where $\bar{e}_{i, k}=\hat{\imath}_{s, k}-\bar{l}_{s, k}, \bar{e}_{\psi, k}=\hat{\psi}_{r, k}-\bar{\psi}_{r, k}$, and $\Delta A=\hat{A}-A=\left[\begin{array}{cc}\Delta A_{11} & \Delta A_{12} \\ \Delta A_{21} & \Delta A_{22}\end{array}\right]$.

By taking the Laplace transform of (61) and (62), it results

$$
\begin{gathered}
{\left[s I-\left(A_{11}-K\right)\right] \bar{e}_{i, k}=A_{12} \bar{e}_{\psi, k}+\Delta A_{12} \hat{\psi}_{r, k}+\Delta A_{11} \hat{\iota}_{s, k}} \\
{\left[s I-A_{22}\right] \bar{e}_{\psi, k}=A_{21} \bar{e}_{i, k}+\Delta A_{22} \hat{\psi}_{r, k}}
\end{gathered}
$$

From (63) and (64), the current error in terms of the stator resistance variation can be represented by

$$
e_{i, R_{s, k}}=G_{R}(s) \cdot \hat{l}_{s, k} \Delta R_{s, k}
$$

where

$$
G_{R}(s)=\frac{\left[s I-A_{22}\right]}{\sigma L_{s}}\left[s^{2} I+s\left(K-A_{11}-A_{22}\right)-A_{22}\left(K-A_{11}-\frac{A_{21}}{\varepsilon}\right)\right]^{-1}
$$

The error relationship in (65) can also be represented by

$$
\left[\begin{array}{l}
e_{d, k} \\
e_{q, k}
\end{array}\right]=\left[\begin{array}{ll}
G_{R 11}(s) & G_{R 12}(s) \\
G_{R 21}(s) & G_{R 22}(s)
\end{array}\right]\left[\begin{array}{c}
\left|\hat{\iota}_{s, k}\right| \\
0
\end{array}\right] \Delta R_{s, k}
$$

By considering only the components of $d$-axis, it gives

$$
e_{d, k}=\left|\hat{\imath}_{s, k}\right| G_{R 11}(s) \Delta R_{s, k}
$$

Thus, $G_{R 11}$ is the unique transfer function utilized in stability analysis of the resistance estimation process. $G_{R 11}$ can be obtained via manipulating (66) as follows

$$
G_{R 11}(s)=\frac{s^{3}+\left(m_{1}+1 / \tau_{r}\right) s^{2}+\left(m_{1} / \tau_{r}+\omega_{\bar{\psi}_{s, k}}\left(2 \omega_{\bar{\psi}_{r, k}}+m_{2}\right)-m_{4}\right) s+\omega_{\bar{\psi}_{s, k}}\left(\omega_{\bar{\psi}_{r, k}} m_{1}+m_{4}\right)-m_{4} / \tau_{r, k}}{\sigma L_{s}\left[\left(s^{2}+m_{1} s-\omega_{\bar{\psi}_{r, k}}^{2}-\omega_{\bar{\psi}_{r, k}} m_{2}+m_{3}\right)^{2}+\left(\left(2 \omega_{\bar{\psi}_{r, k}}+m_{2}\right) s+\omega_{\bar{\psi}_{r, k}} m_{1}+m_{4}\right)^{2}\right]}
$$

where $m_{1}=\left(\frac{R_{s}}{\sigma L_{s}}+\frac{L_{m}^{2}}{\sigma L_{s} L_{r} \tau_{r}}+\frac{1}{\tau_{r}}+K_{1}\right), m_{2}=\left(K_{2}-\omega_{m e}\right), m_{3}=\left(\frac{1}{\tau_{r}}\left(\frac{R_{s}}{\sigma L_{s}}+\frac{L_{m}^{2}}{\sigma L_{s} L_{r} \tau_{r}}-\frac{L_{m}}{\varepsilon \tau_{r}}+\right.\right.$ $\left.\left.K_{1}\right)+K_{2} \omega_{m e}\right), \quad m_{4}=\left(\frac{K_{2}}{\tau_{r}}-\omega_{m e}\left(\frac{R_{s}}{\sigma L_{s}}+\frac{L_{m}^{2}}{\sigma L_{s} L_{r} \tau_{r}}-\frac{L_{m}}{\varepsilon \tau_{r}}+K_{1}\right)\right)$, and $K_{1}, K_{2}$ are the feedback gains. 
The closed-loop system of stator resistance estimation can now be constructed as in Figure 5 .

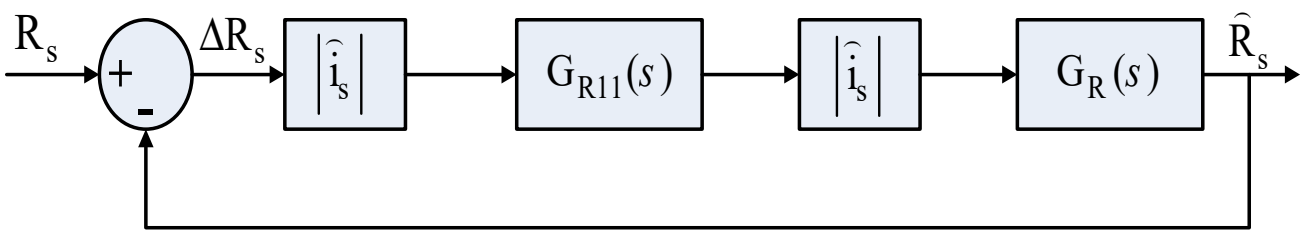

Figure 5. Stator resistance estimation loop.

The allocation of dominant-pole/zero of $G_{R 11}(s)$ is illustrated through plotting the root-locus as in Figure 6. It is noticed that all dominant zeros and poles are positioned in the left-hand side of the complex plane. Therefore, the stator resistance estimator is stable.

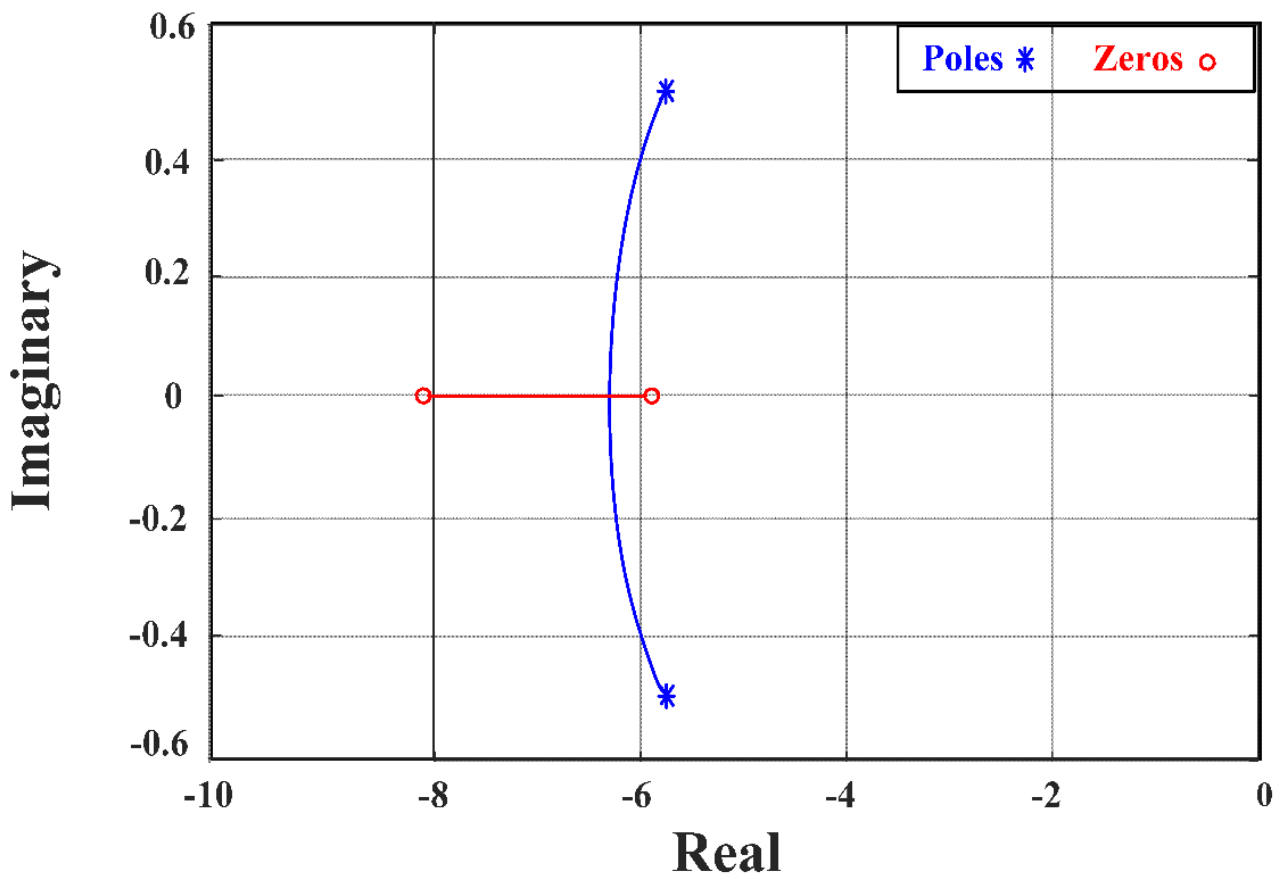

Figure 6. Allocation of dominant pole-zero of $G_{R 11}$.

After designing the sensorless L-SMO, the overall control scheme can be structured as illustrated in Figure 7. The control system starts with measuring the voltage and current of the stator windings. Then, the system samples the measured signals to be used later by the controller. The inputs of the L-SMO are the stator voltage and stator current, while the observed signals are the speed, stator current, rotor flux and stator resistance. The estimated speed is employed for predicting the currents and rotor flux at instant $(k+1) T_{S}$ and for terminating the speed loop as well. The predicted speed signal is compared with the reference speed and the error is applied to a speed regulator to provide the reference torque signal at $(k+1) T_{s}$. After that, the calculated values of rotor flux and stator current are fed with the reference signals of torque and rotor flux to the designed back-stepping regulator described in Section 3 which finally provides the reference voltages $u_{d s, k+1}^{*}$ and $u_{q s, k+1}^{*}$ at its output terminals. The reference voltages are utilized with the feedback voltages $u_{d s, k+1}$ and $u_{q s, k+1}$ in (28), which provides the optimal voltages after accomplishing the optimization action. The fed back voltages are captured via utilizing a memory buffering unit as illustrated in Figure 7. 


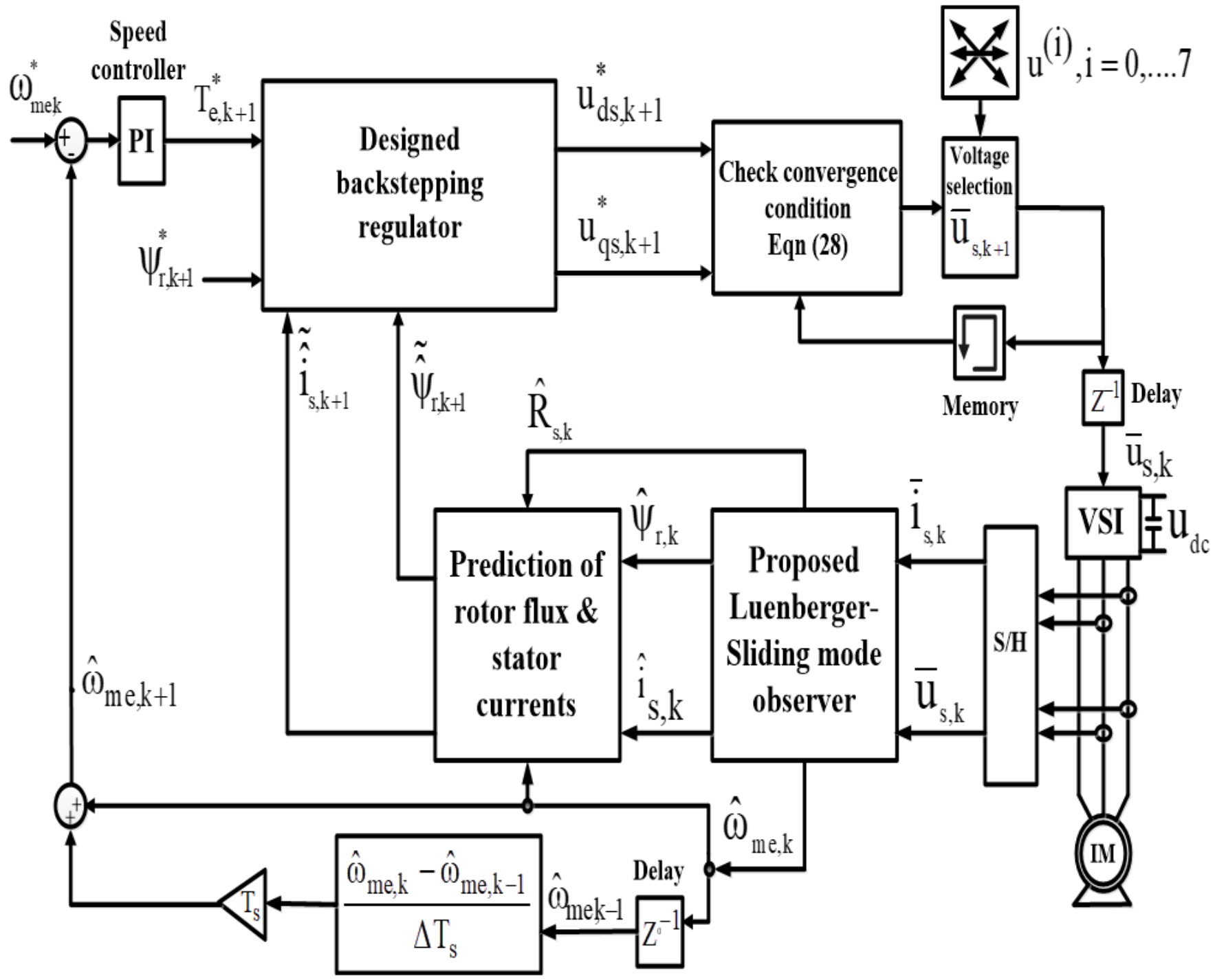

Figure 7. Overall control scheme for IM drive.

\section{Test Results}

To test the validness of the PVC control algorithm, a comparative analysis has been performed among the performances of IM under the PTC and novel PVC algorithms. The tests are carried out using Matlab/Simulink when the speed is changed from 800 RPM down to 400 RPM down to 30 RPM at $t=0 \mathrm{~s}, t=2 \mathrm{~s}$ and $t=4 \mathrm{~s}$. The IM is loaded with $5 \mathrm{Nm}$ (half of rated torque) at starting. After that at time $t=3.5 \mathrm{~s}$, the full load torque $(10 \mathrm{Nm})$ is used. The reference flux for the PTC is set to the nominal flux (1 Vs), whereas for the PVC, the reference rotor flux is assigned to $0.9765 \mathrm{Vs}$ to emulate the same conditions of PTC. The IM drive data are presented in Table A1 in Appendix A.

Firstly, the PTC performance is tested as illustrated in Figures 8-10 with the acceleration, developed torque, and flux profiles under the PTC. From these figures, it is observed that the ripples are remarkable in the torque and flux values. Moreover, it can be noticed from the speed profile that the proposed L-SMO observer has managed in tracking the speed with high precision. In Figure $11 a, b$, the actual and estimated rotor flux $(\alpha-\beta)$ components are presented which confirm the effectiveness of the proposed L-SMO in definite estimation of rotor flux. In Figure $12 \mathrm{a}, \mathrm{b}$, the actual and estimated stator current $(\alpha-\beta)$ components are shown, which reconfirm the validity of the proposed L-SMO observer. In Figure $13 a, b$, the actual and estimated stator resistances and their relevant observation error 
are shown. From this figure, it is realized that the resistance variation is strictly observed thanks to the L-SMO, which is reflected in the robustness of the entire system.

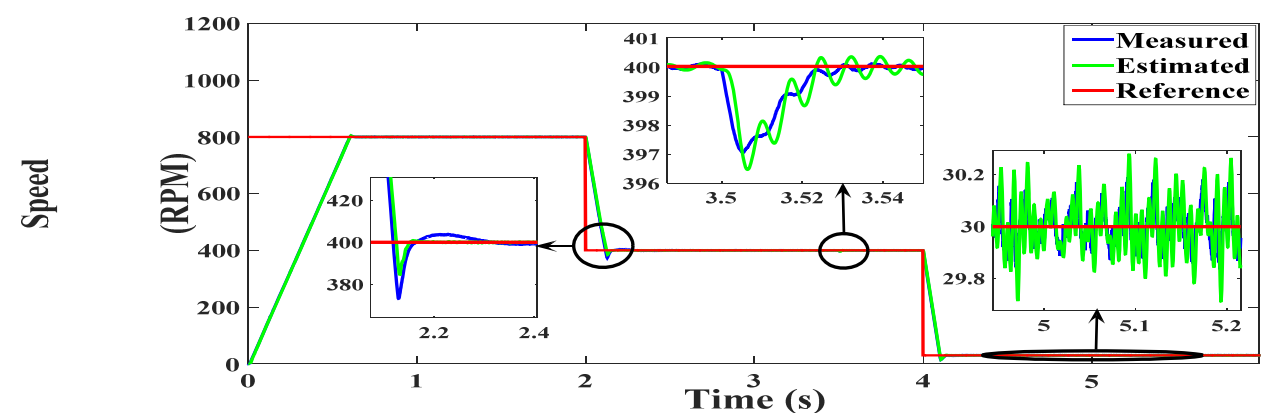

Figure 8. Rotor speed profile under PTC approach (RPM).

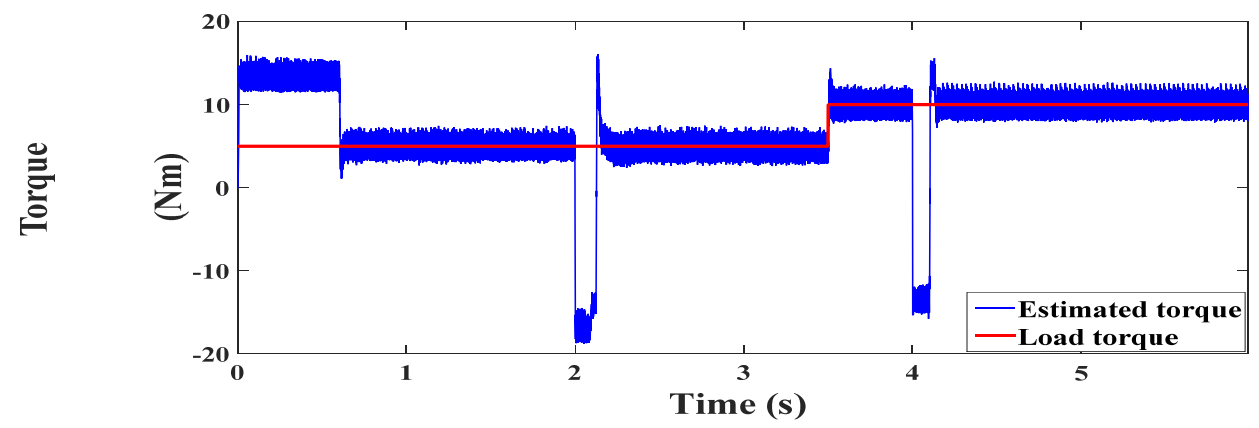

Figure 9. Torque profile under PTC approach (Nm).

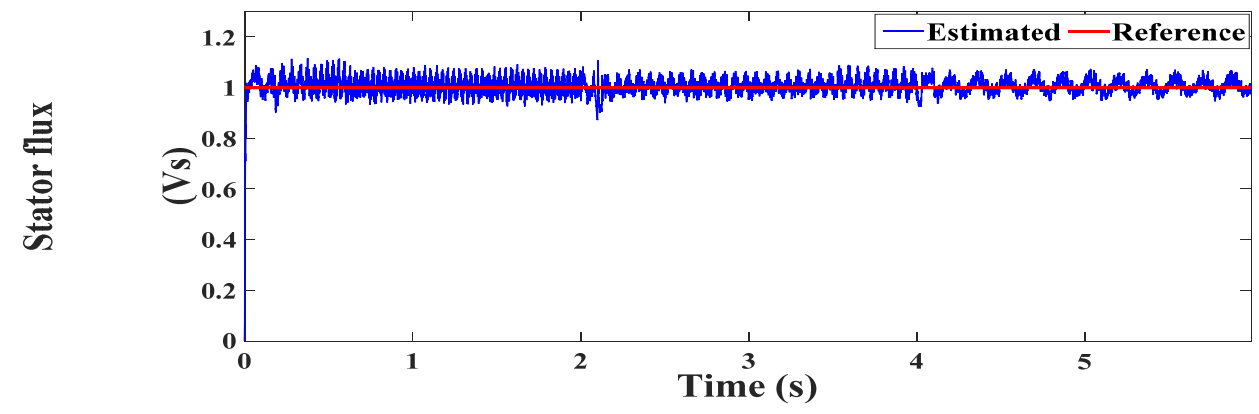

Figure 10. Stator flux profile under PTC approach (Vs).

The test results for the constructed PVC approach using the L-SMO estimator are also presented in Figures 14-16 which show the actual and estimated speed profiles, the developed torque, and estimated stator flux, respectively. The L-SMO confirms its validity in the estimation of the speed with minimum deviation even at very low speed operation. Moreover, it can be noticed that the accompanied ripples in the torque and flux values are efficiently suppressed in comparison with their values under PTC. Figure 17a,b show the actual and estimated values of $(\alpha-\beta)$ components of rotor flux, while Figure $18 \mathrm{a}, \mathrm{b}$ illustrate the actual and estimated values of $(\alpha-\beta)$ stator current components. In addition, Figure 19a,b present the actual and estimated values of stator resistance and their related estimation error. From these figures, it is realized that the L-SMO has succeeded in achieving very good tracking for the required variables, which improved the prediction process, and thus the system response is also enhanced. Alternatively, the harmonics in the current components under the PTC are noticeable which can be investigated through Figure 20a,b, which show the THD spectrum analysis.. The THD spectrum analysis for the current components under the proposed PVC is also shown in Figure 21a,b, which clarifies the reduction of the current THD when considering the designed PVC. 


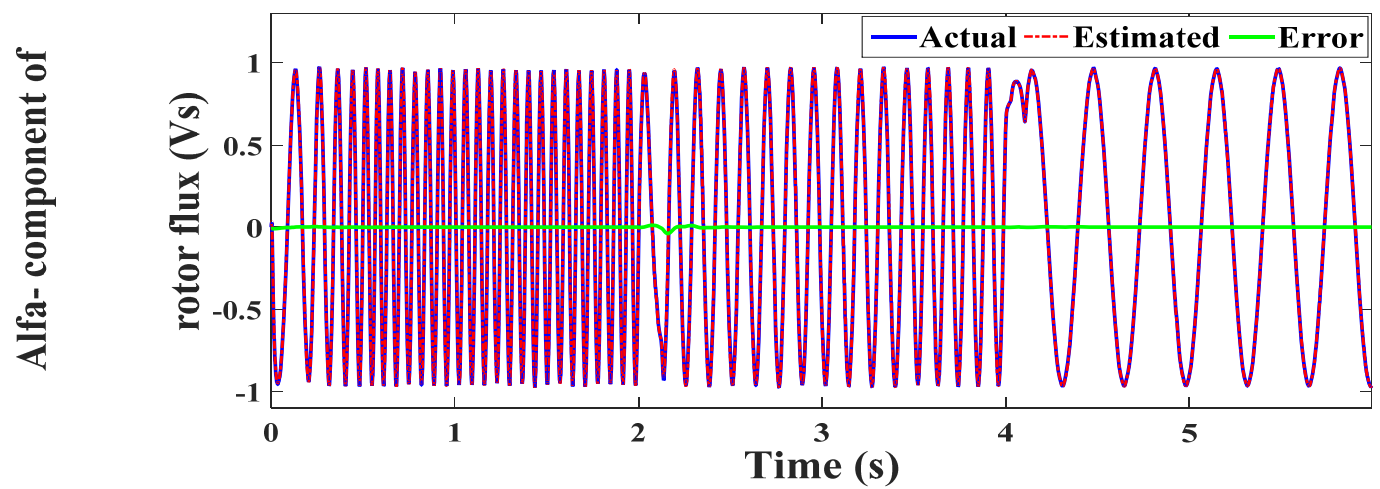

(a)

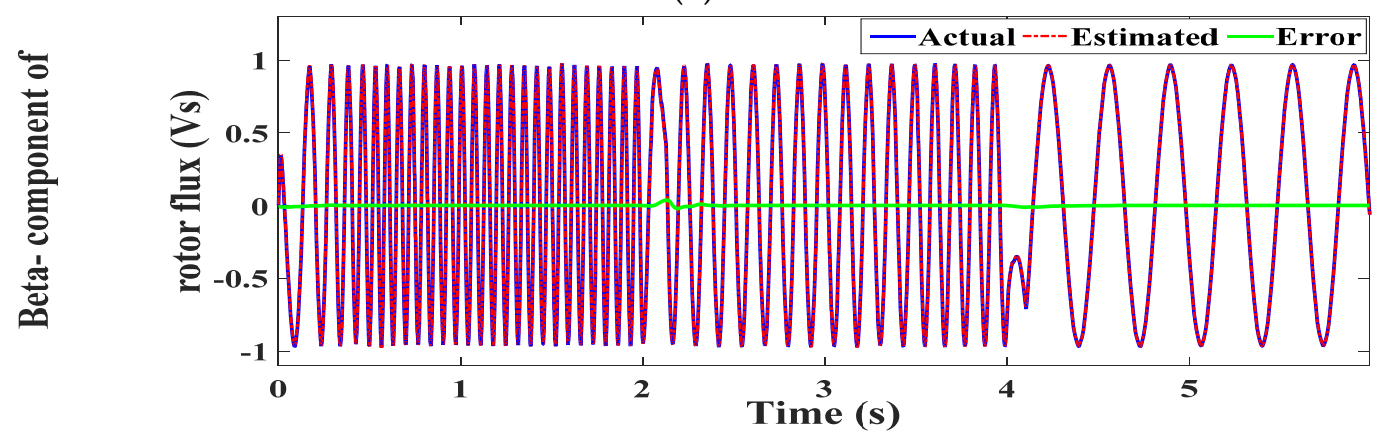

(b)

Figure 11. (a). Alfa-component of rotor flux under PTC approach (Vs), (b). Beta-component of rotor flux under PTC approach (Vs).

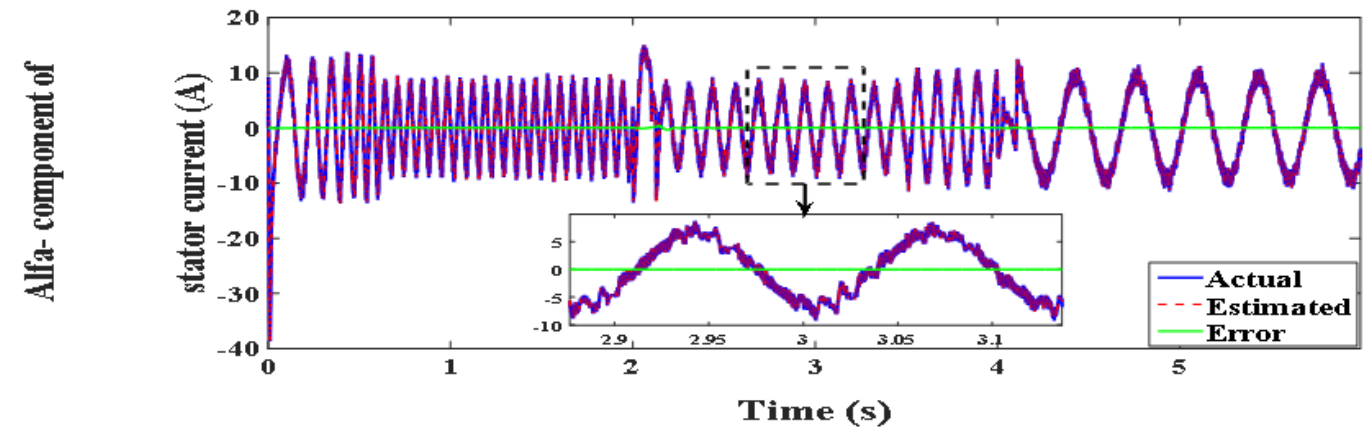

(a)

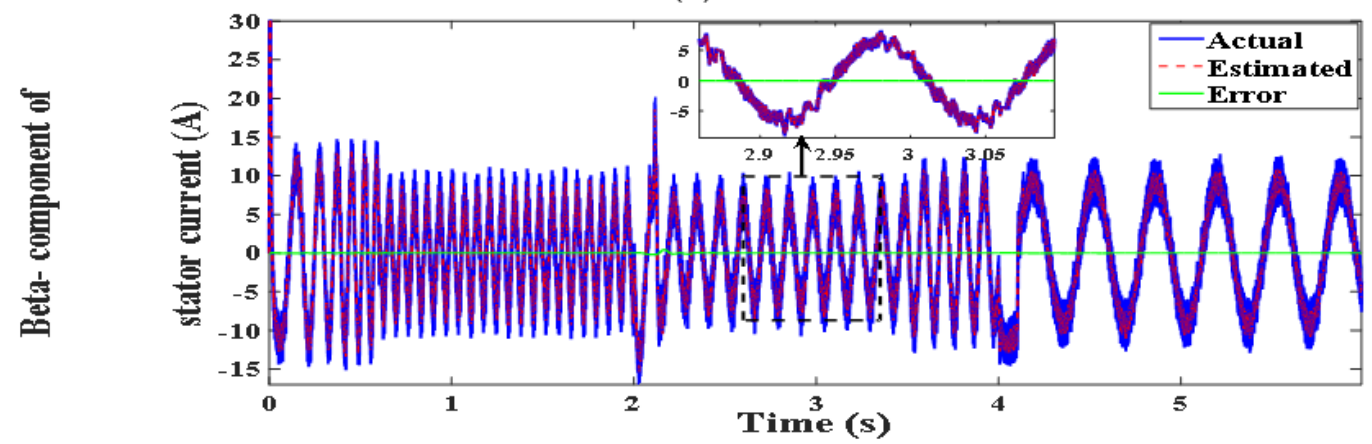

(b)

Figure 12. (a). Alfa-component of stator current under PTC approach (A), (b). Beta-component of stator current under PTC approach (A). 


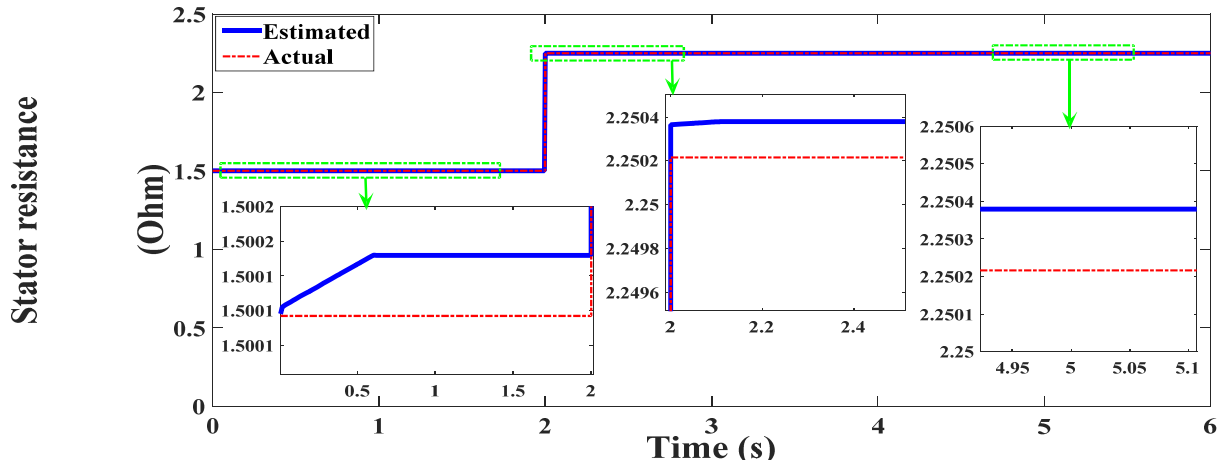

(a)

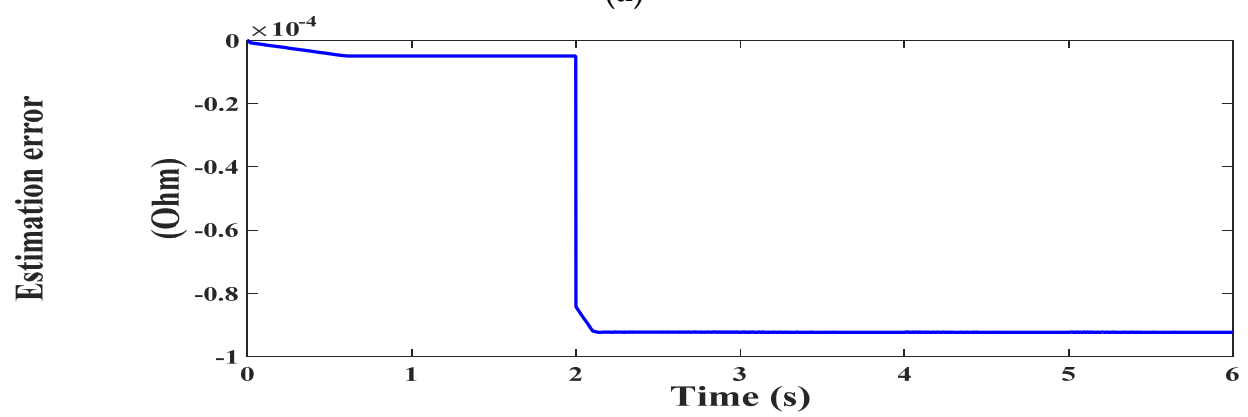

(b)

Figure 13. (a). Stator resistance variation under PTC $(\Omega)$, (b). Rs estimation error under PTC $(\Omega)$.

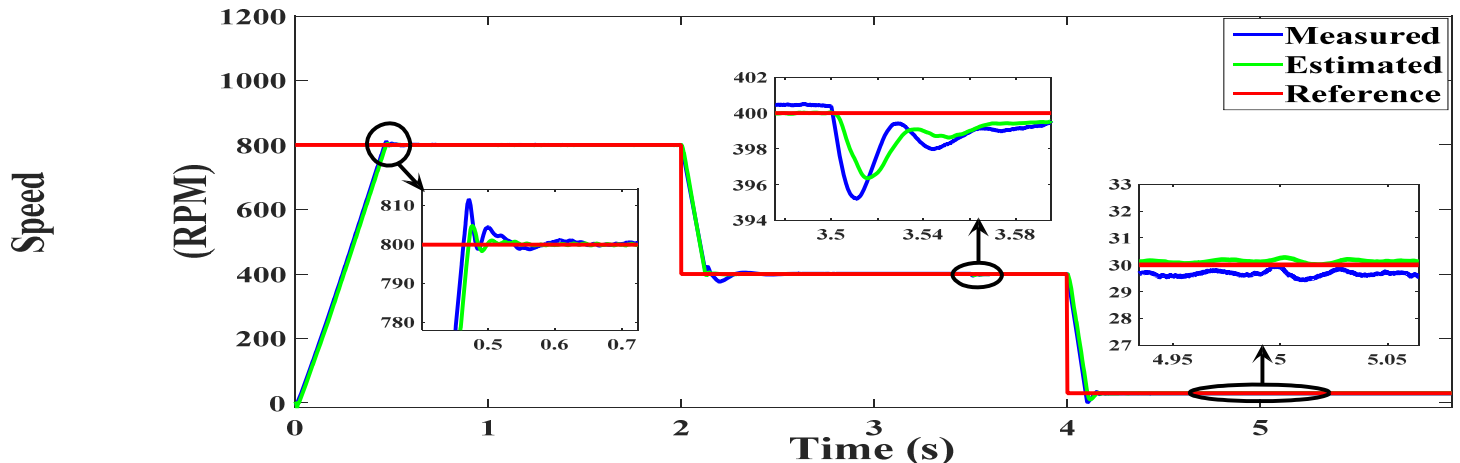

Figure 14. Rotor speed profile under proposed PVC approach (RPM).

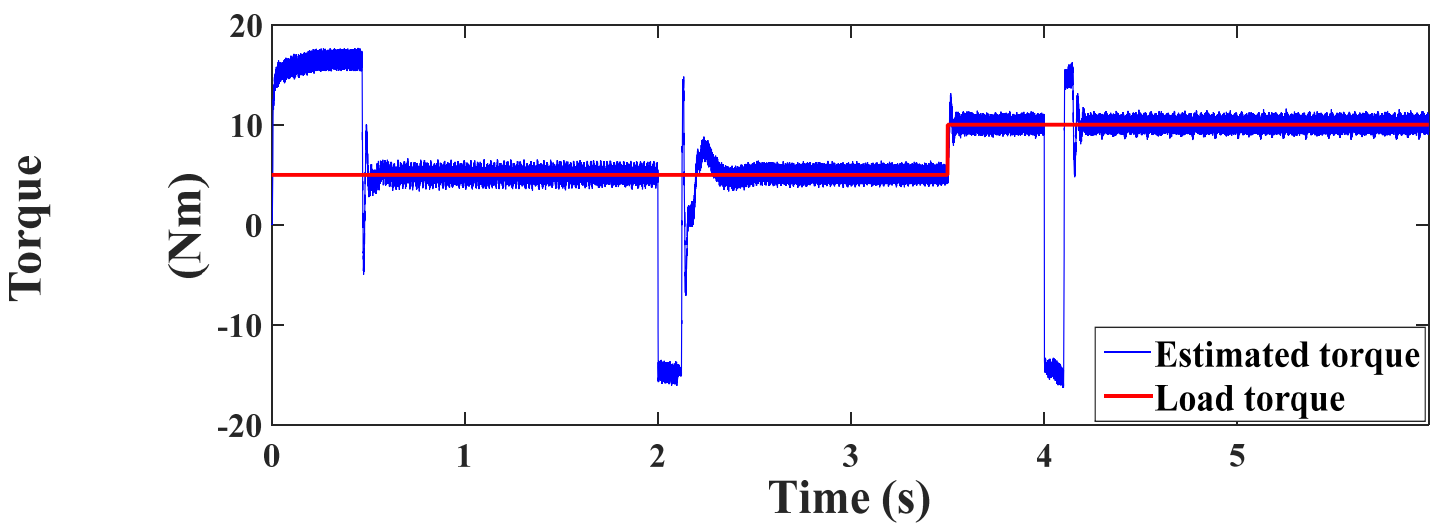

Figure 15. Torque profile under proposed PVC approach (Nm). 


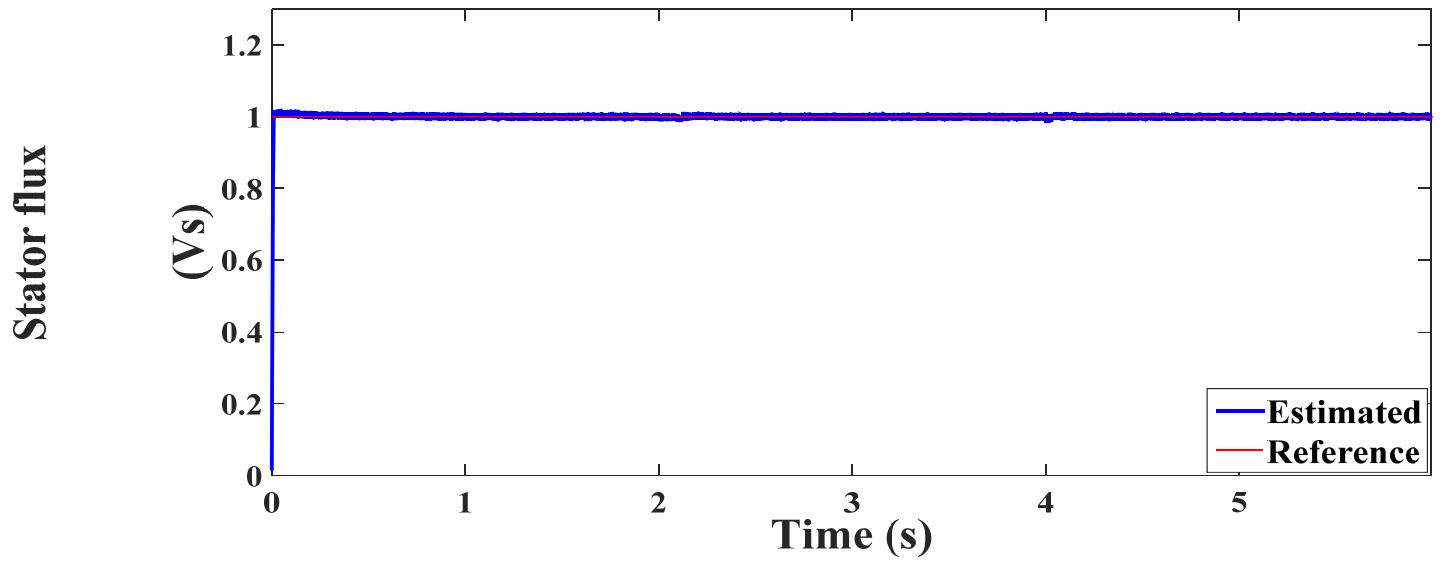

Figure 16. Stator flux profile under proposed PVC approach (Vs).

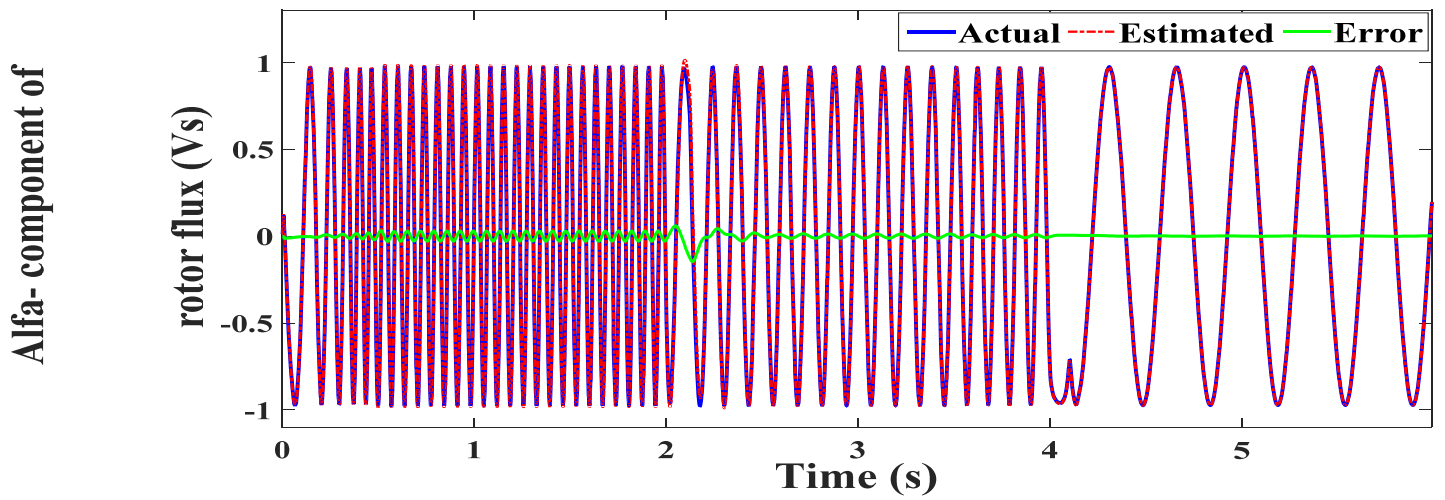

(a)

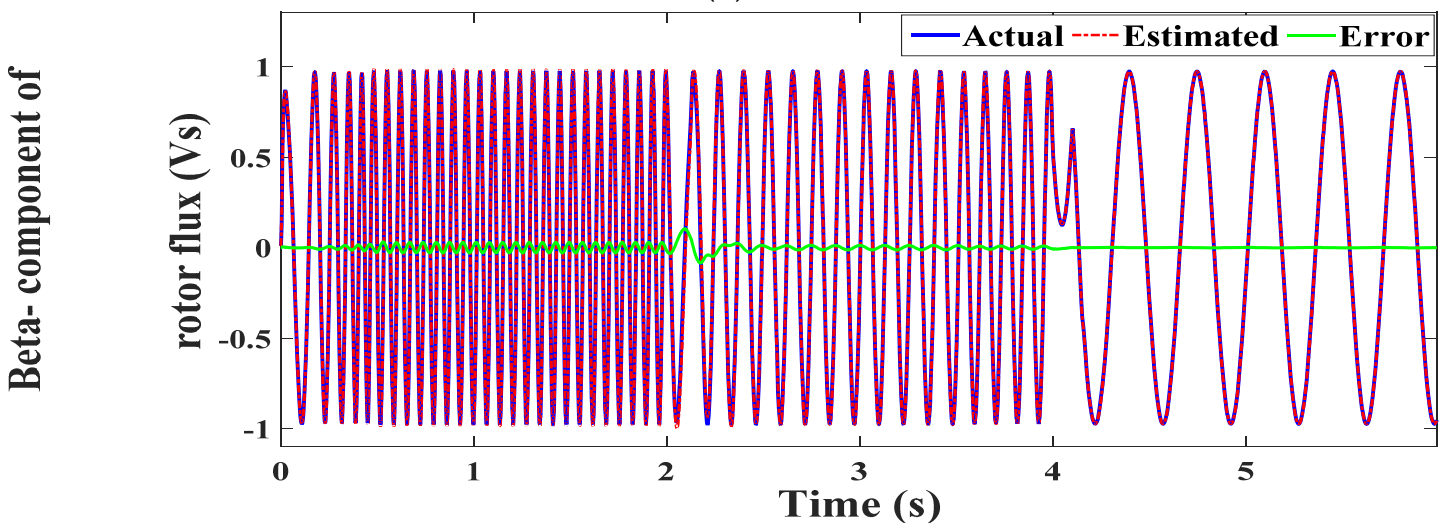

(b)

Figure 17. (a). Alfa-component of rotor flux under proposed PVC approach (Vs), (b). Beta-component of rotor flux under proposed PVC approach (Vs). 


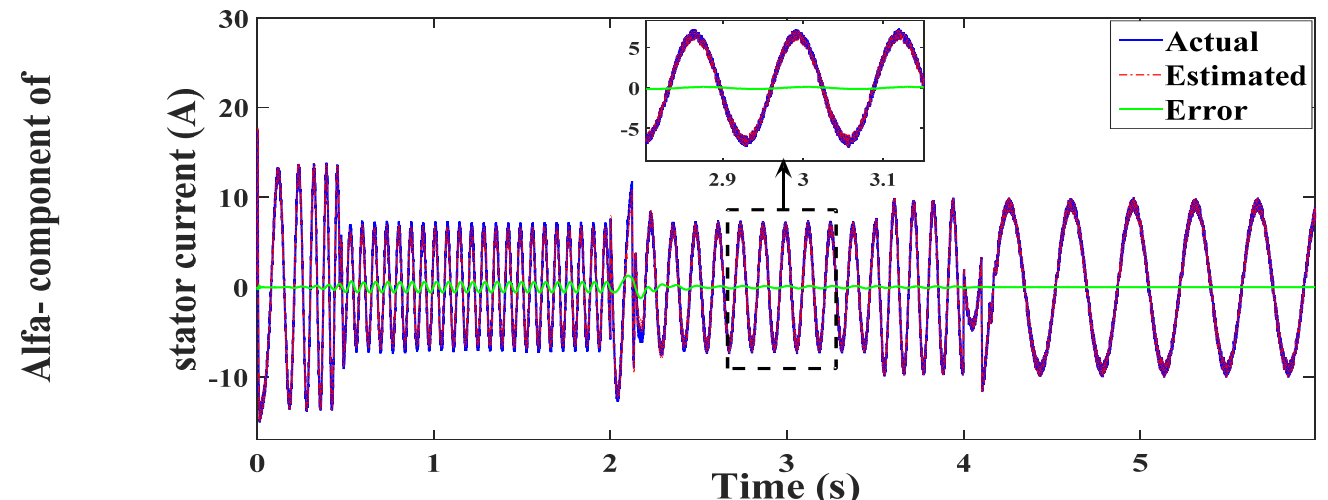

(a)

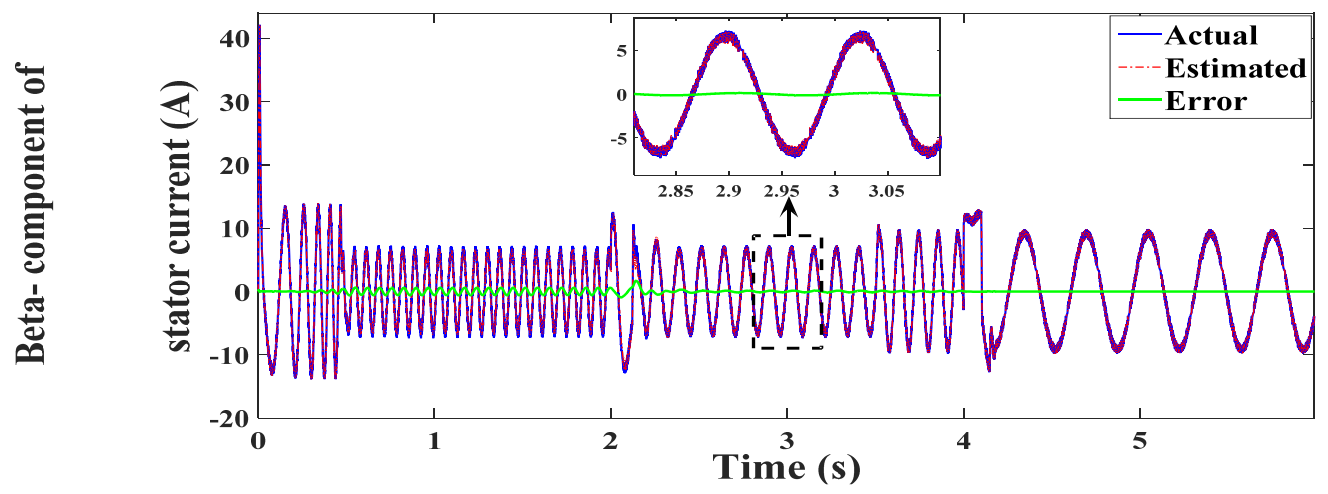

(b)

Figure 18. (a). Alfa-component of stator current under proposed PVC (A), (b). Beta-component of stator current under proposed PVC (A).

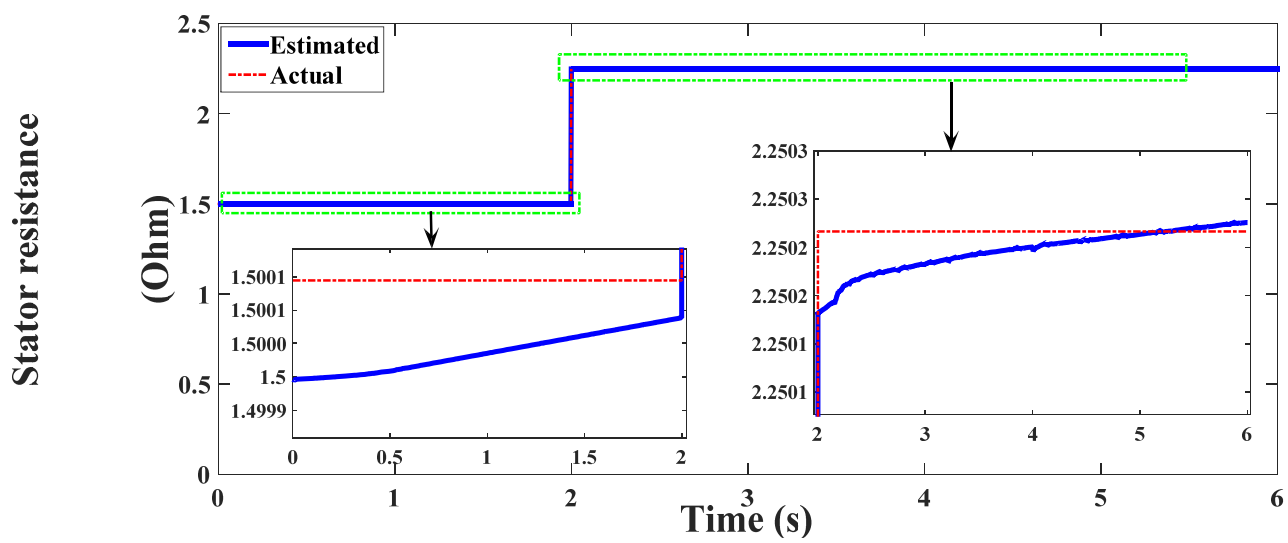

(a)

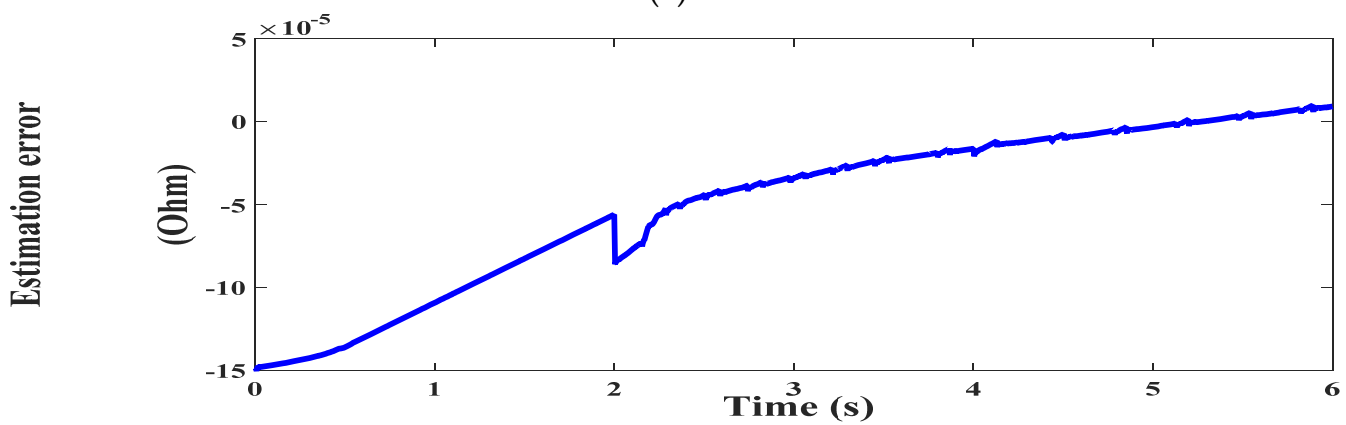

(b)

Figure 19. (a). Stator resistance variation under $\operatorname{PVC}(\Omega)$, (b). Rs estimation error under PVC $(\Omega)$. 


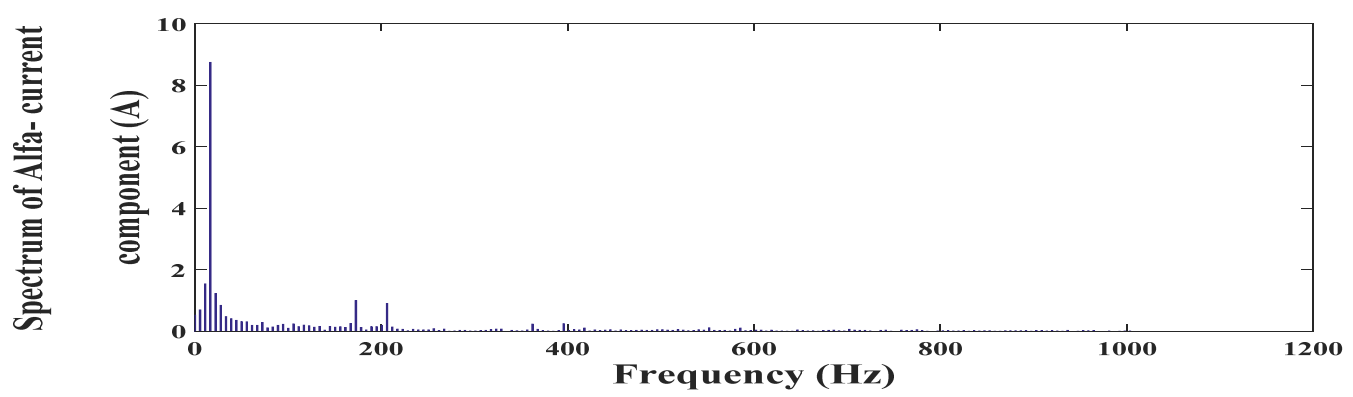

(a)

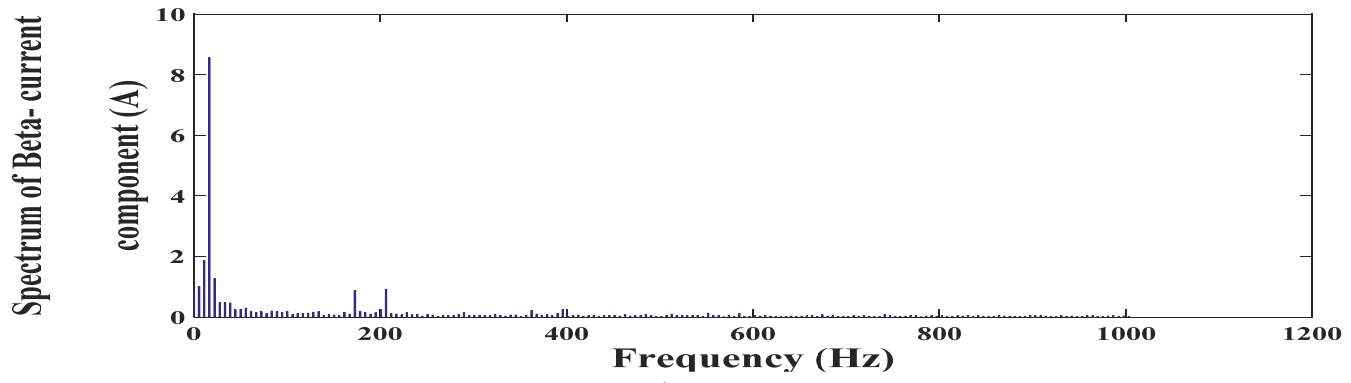

(b)

Figure 20. (a). FFT spectrum of $\alpha$-component of stator current under PTC, (b). FFT spectrum of $\beta$-component of stator current under PTC.

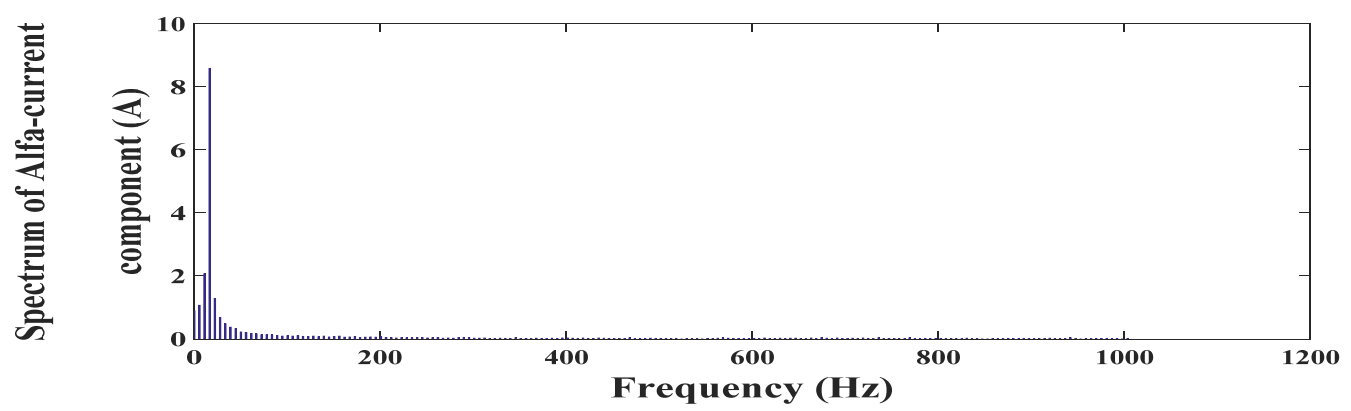

(a)

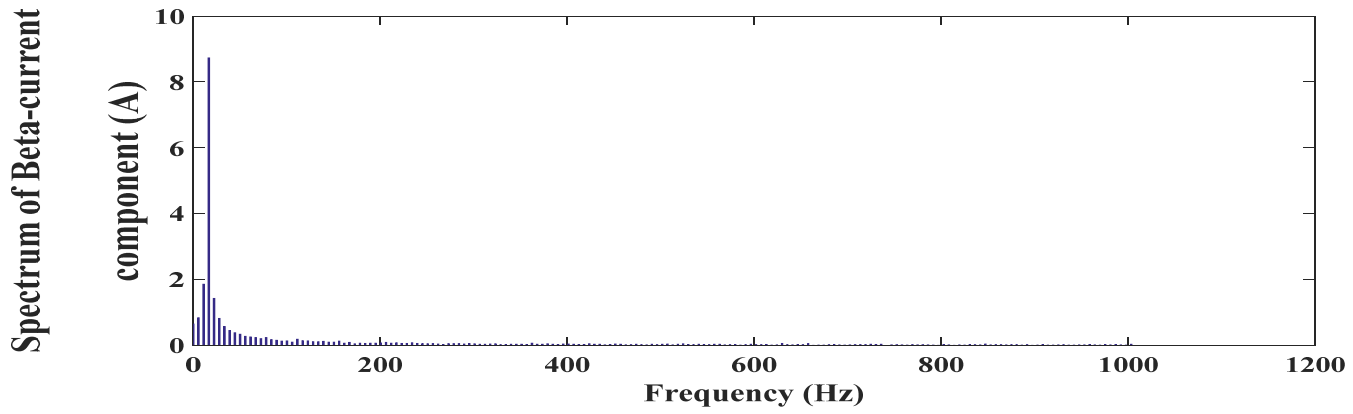

(b)

Figure 21. (a). FFT spectrum of $\alpha$-component of stator current for proposed PVC, (b). FFT spectrum of $\beta$-component of stator current for proposed PVC.

The statistics for the FFT analysis of the stator current for the two control approaches are presented in Table 1, which shows a significant reduction of THD under the PVC approach. 
Table 1. Spectrums of currents under PTC and PVC techniques.

\begin{tabular}{ccc}
\hline \multirow{2}{*}{ Algorithm } & \multicolumn{2}{c}{ Current Spectrums } \\
\cline { 2 - 3 } & $\boldsymbol{i}_{\boldsymbol{\alpha}}$ & $\boldsymbol{i}_{\beta s}$ \\
\hline \multirow{2}{*}{ PTC } & Fundamental $(8.74485 \mathrm{~A})$ & Fundamental $(8.55044 \mathrm{~A})$ \\
& $T H D=3.23 \%$ & $T H D=3.15 \%$ \\
\hline \multirow{2}{*}{ Designed scheme } & Fundamental $(8.5752 \mathrm{~A})$ & Fundamental $(8.72869 \mathrm{~A})$ \\
& $T H D=2.50 \%$ & $T H D=2.33 \%$ \\
\hline
\end{tabular}

Thanks to the simple construction of the proposed cost function used by the PVC approach, the number of inverter switching actions is significantly reduced and this can be clarified through the comparison made in Table 2 in terms of the number of switchings and switching frequencies under both PTC and formulated PVC as well.

Table 2. Switching frequencies and commutations for the two controllers.

\begin{tabular}{ccc}
\hline Controller & Commutations & Switching Frequency \\
\hline PTC & 11,540 & $1.923 \mathrm{KHz}$ \\
\hline Designed scheme & 8941 & $1.49 \mathrm{KHz}$ \\
\hline
\end{tabular}

To check the effectiveness of the estimation of $\hat{\tau}_{r, k}$ and the angular slip and verifying the correct orientation of the rotor flux, Figure 22a,b shows the estimated and actual values of the angular slip frequencies which present a precise matching between the two signals and which confirm the correctness of the field orientation under the estimation process. This fact can be also confirmed by Figure 23, which shows the actual and estimated values of rotor time constant and from which it can be confirmed that the precise estimation and field orientation are both ensured. Moreover, Figure 24 confirms that the $d-q$ rotor flux components are correctly decoupled, which means that the field orientation is appropriately achieved.

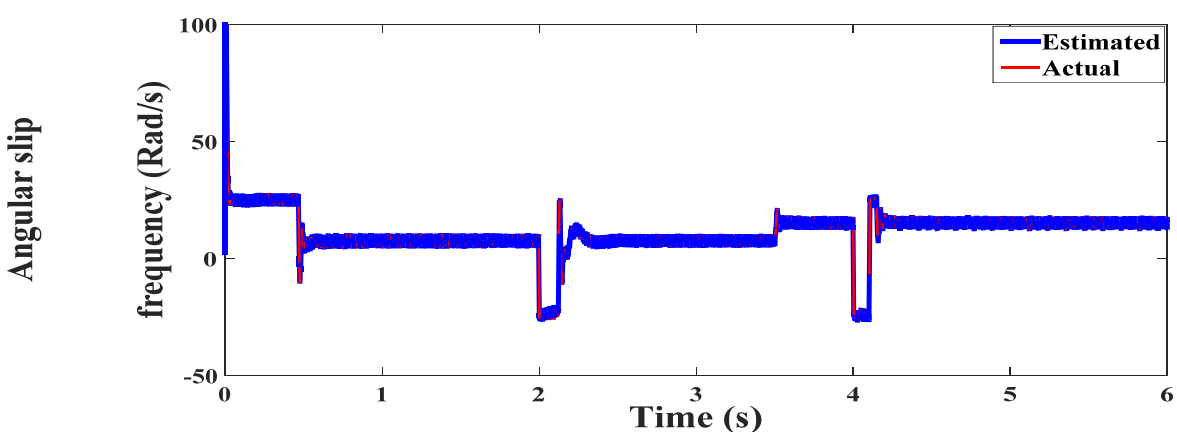

(a)

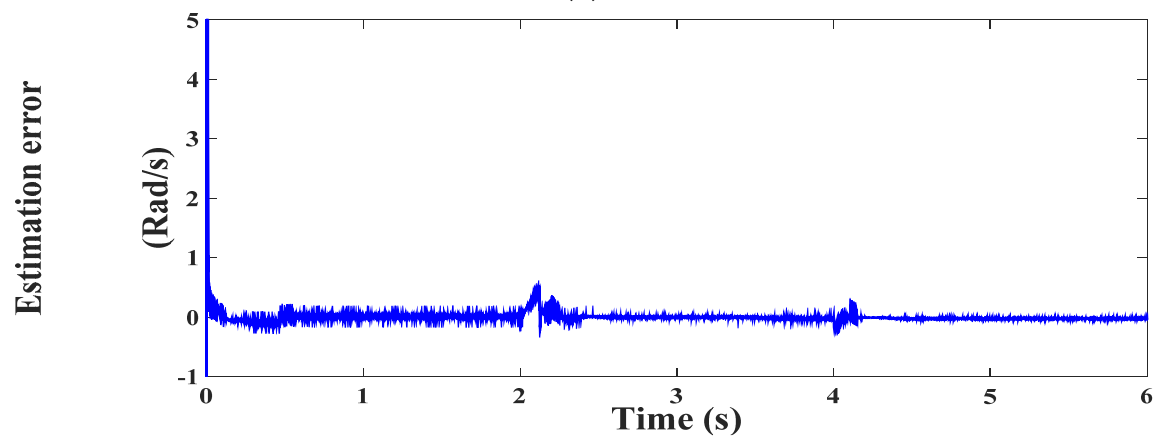

(b)

Figure 22. (a) Estimated and actual slip frequency. (b) estimation error. 


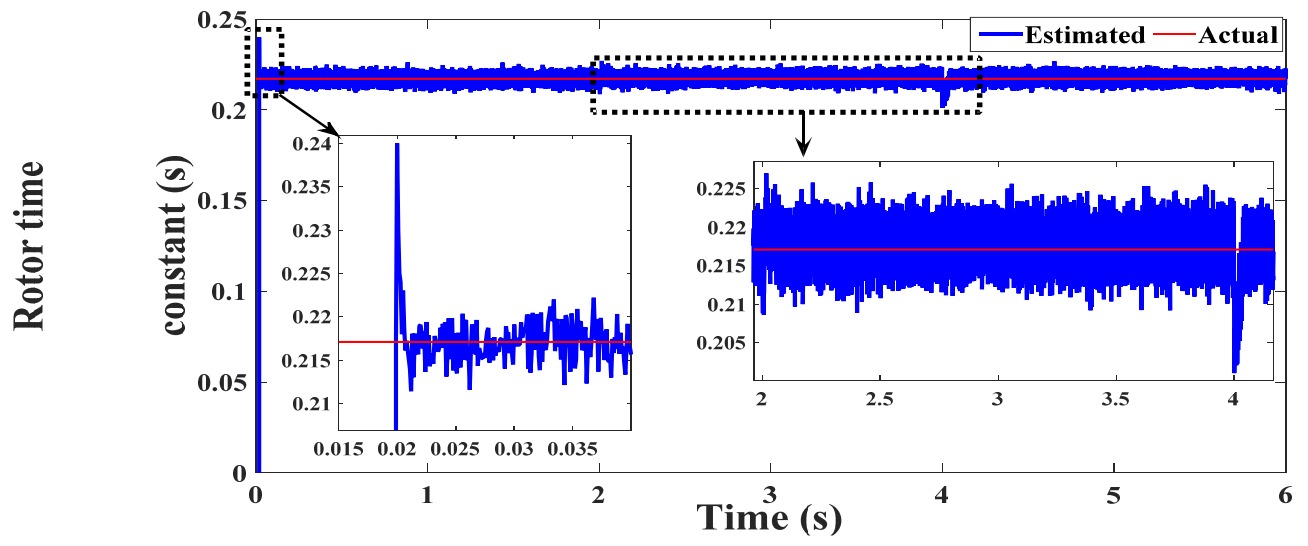

Figure 23. Estimated and actual rotor time constant.

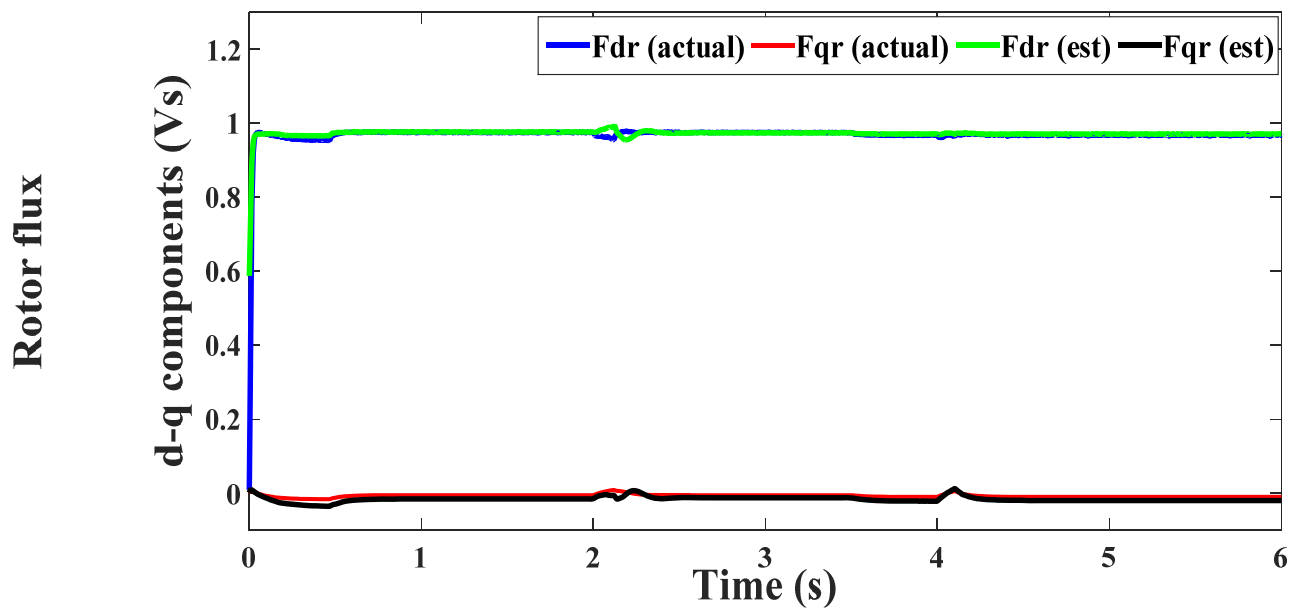

Figure 24. Estimated and actual rotor flux $d-q$ components.

Moreover, a comparison is made between the torque and flux curves for the two control approaches to show the improved performance of the IM under the proposed PVC procedure. This can be viewed through Figures 25 and 26 .

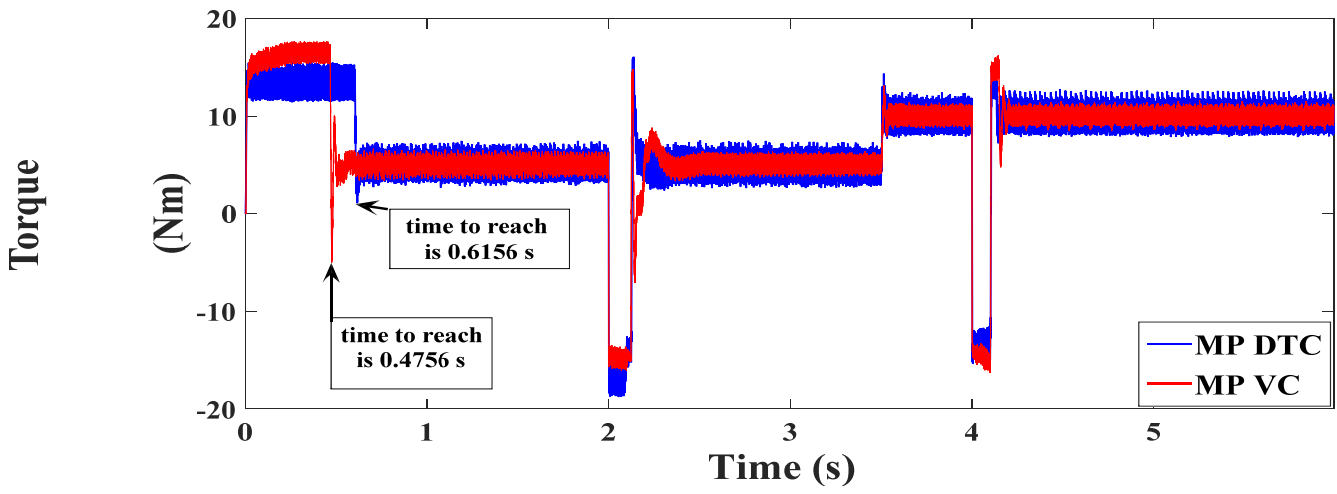

Figure 25. Torque profiles for the two control algorithms (Nm). 


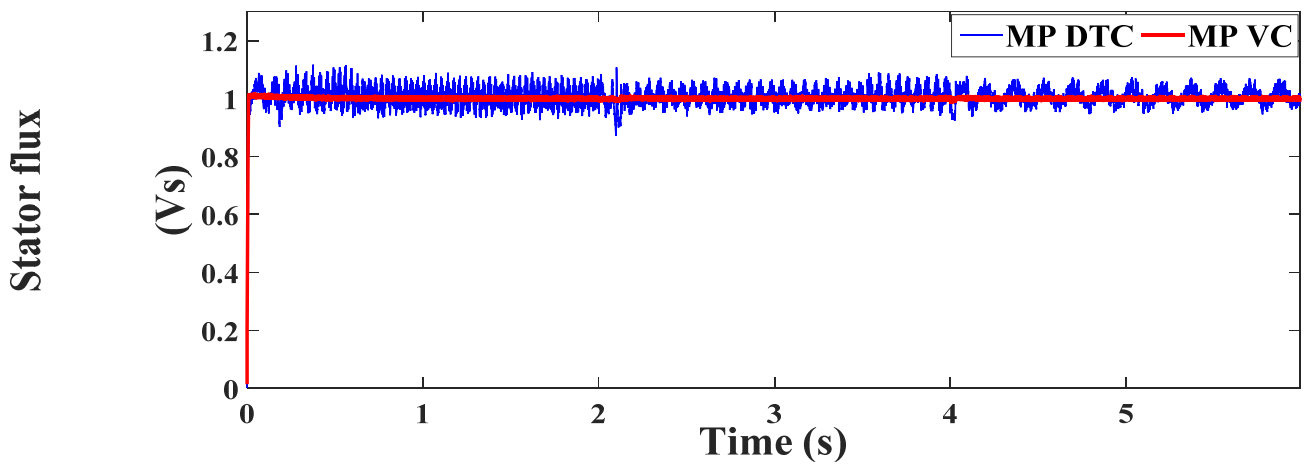

Figure 26. Stator flux profiles for the two control algorithms (Vs).

\section{Conclusions}

The paper has proposed a new PVC technique for improving the dynamics of a sensorless IM drive. The proposed PVC utilizes a new convergence condition. The used convergence condition is very simple and does not incorporate any weighting values as usually used by the traditional predictive torque control (PTC) approach. Moreover, the designed convergence condition does not involve any estimated terms, which enhances the control response and increases the robustness against the system's uncertainties. A Luenberger-sliding mode observer (L-SMO) is utilized to observe several system's variables such as speed, rotor flux, stator current and stator resistance as well. Checking the validity of the L-SMO has been investigated for different operating frequencies. To visualize the enhanced dynamics of IM drive under the proposed PVC, a comparison is made with the PTC, which reflected the remarkable improvements of the IM dynamics under the proposed VC in the forms of reduced torque, flux, and current ripples, and reduced switching actions as well. As a summary the following items summarize the work undertaken for the paper, its outputs, and the further studies that can be performed in the future:

- The paper formulated a new PVC scheme to be used as an alternative to the classic PTC.

- The operation principle of the designed PVC is based on regulating the stator voltage components instead of regulating the torque and flux as in PTC.

- The back-stepping theory is utilized to generate the voltage commands needed by the designed cost function of the PVC.

- The designed PVC is used with a L-SMO observer to enhance the overall system robustness.

- The designed L-SMO is performed systematically, describing the gain selection mechanism and checking the stability of the observer.

- Extensive dynamic analysis is performed for the PTC and designed PVC to outline the superiority of the proposed controller.

- Ripple reduction, faster dynamic response, reduced number of commutations, and reduced THD are the remarkable improvements achieved by the PVC.

- For future study, the designed PVC scheme can be utilized with different machine drives after considering the principle of operation and physical model of each type.

Author Contributions: Conceptualization, M.A.M., H.E. and N.V.Q.; methodology, M.A.M. and A.A.A.; software, M.A.M., H.E. and H.H.A.; validation, M.A.M., N.V.Q. and H.E.; formal analysis, H.E., M.A.M., A.A.A. and H.H.A.; investigation, N.V.Q., H.E. and H.H.A.; resources, M.A.M., H.E.; data curation, M.A.M., A.A.A. and N.V.Q.; writing-original draft preparation, M.A.M., H.E. and H.H.A.; writing-review and editing, N.V.Q., H.H.A., M.A.M. and A.A.A.; visualization, M.A.M., H.E. and A.A.A.; supervision, M.A.M., N.V.Q. and H.H.A.; project administration, M.A.M. and N.V.Q.; funding acquisition, M.A.M. and N.V.Q. All authors have read and agreed to the published version of the manuscript.

Funding: This work was supported by Lac Hong University, Vietnam. 
Conflicts of Interest: The authors declare no conflict of interest.

\section{Appendix A}

Table A1. IM and control system parameters.

\begin{tabular}{cccc}
\hline Constant & Value & Constant & Value \\
\hline Power & $3000 \mathrm{~W}$ & Leakage factor & 0.07576 \\
\hline Stator resistance & $1.50 \Omega$ & $K_{i}, K_{p}$ (Speed regulator) & 1267 and 14.24 \\
\hline Rotor resistance & $0.85 \Omega$ & $k_{1}, k_{2}, k_{3}, k_{4}$ & $450,200,150,55$ \\
\hline Stator inductance & $178.5 \mathrm{mH}$ & $a$ & 200 \\
\hline Rotor inductance & $184.5 \mathrm{mH}$ & $p$ & 1 \\
\hline Mutual inductance & $174.5 \mathrm{mH}$ & DC voltage & $300 \mathrm{~V}$ \\
\hline
\end{tabular}

\section{References}

1. Holakooie, M.; Ojaghi, M.; Taheri, A. Direct Torque Control of Six-Phase Induction Motor with a Novel MRAS-Based Stator Resistance Estimator. IEEE Trans. Ind. Electron. 2018, 65, 7685-7696. [CrossRef]

2. Ziaeinejad, S.; Sangsefidi, Y.; Nabi, H.; Shoulaie, A. Direct Torque Control of Two-Phase Induction and Synchronous Motors. IEEE Trans. Ind. Electron. 2013, 28, 4041-4050. [CrossRef]

3. Toh, C.; Idris, N.; Yatim, A. Constant and high switching frequency torque controller for DTC drives. IEEE Power Electron. Lett. 2005, 3, 76-80. [CrossRef]

4. Lin, X.; Huang, W.; Jiang, W.; Zhao, Y.; Zhu, S. A Stator Flux Observer with Phase Self-Tuning for Direct Torque Control of Permanent Magnet Synchronous Motor. IEEE Trans. Ind. Electron. 2020, 35, 6140-6152. [CrossRef]

5. Pandit, J.; Aware, M.; Nemade, R.; Levi, E. Direct Torque Control Scheme for a Six-Phase Induction Motor with Reduced Torque Ripple. IEEE Trans. Ind. Electron. 2017, 32, 7118-7129. [CrossRef]

6. Gunabalan, R.; Sanjeevikumar, P.; Blaabjerg, F.; Ojo, O.; Subbiah, V. Analysis and Implementation of Parallel Connected TwoInduction Motor Single-Inverter Drive by Direct Vector Control for Industrial Application. IEEE Trans. Ind. Electron. 2015, 30, 6472-6475. [CrossRef]

7. Sira-Ramírez, H.; González-Montañez, F.; Cortés-Romero, J.; Luviano-Juárez, A. A Robust Linear Field-Oriented Voltage Control for the Induction Motor: Experimental Results. IEEE Trans. Ind. Electron. 2013, 60, 3025-3033. [CrossRef]

8. Wang, Z.; Chen, J.; Cheng, M.; Chau, K. Field-Oriented Control and Direct Torque Control for Paralleled VSIs Fed PMSM Drives with Variable Switching Frequencies. IEEE Trans. Ind. Electron. 2016, 31, 2417-2428. [CrossRef]

9. Wang, K.; Li, Y.; Ge, Q.; Shi, L. An Improved Indirect Field-Oriented Control Scheme for Linear Induction Motor Traction Drives. IEEE Trans. Ind. Electron. 2018, 65, 9928-9937. [CrossRef]

10. Masiala, M.; Vafakhah, B.; Salmon, J.; Knight, A. Fuzzy Self-Tuning Speed Control of an Indirect Field-Oriented Control Induction Motor Drive. IEEE Trans. Ind. Appl. 2008, 44, 1732-1740. [CrossRef]

11. Panda, V.; Singh, S. A Three-Level Fuzzy-2 DTC of Induction Motor Drive Using SVPWM. IEEE Trans. Ind. Electron. 2016, 63, 1467-1479.

12. Buja, G.; Kazmierkowski, M. Direct torque control of PWM inverter-fed AC motors-A survey. IEEE Trans. Ind. Electron. 2004, 51, 744-757. [CrossRef]

13. Jnayah, S.; Khedher, A. Fuzzy-Self-Tuning PI Speed Regulator for DTC of Three-Level Inverter fed IM. In Proceedings of the 17th International Multi-Conference on Systems, Signals \& Devices (SSD), Monastir, Tunisia, 23-25 July 2020; pp. 709-714.

14. Yang, J.; Huang, J. Direct torque control system for induction motors with fuzzy speed PI regulator. In Proceedings of the International Conference on Machine Learning and Cybernetics, Guangzhou, China, 18-21 August 2005; pp. 778-783.

15. Meesala, R.; Thippiripati, V. An Improved Direct Torque Control of Three-Level Dual Inverter Fed Open-Ended Winding Induction Motor Drive Based on Modified Look-Up Table. IEEE Trans. Ind. Electron. 2020, 35, 3906-3917.

16. Ajlan, A.; Idris, N.; Lee, S. Improving flux regulation of DTC induction motor drive by modifying the index to the FPGA-based lookup table. In Proceedings of the IEEE Conference on Energy Conversion (CENCON), Kuala Lumpur, Malaysia, 30-31 October 2017; pp. 139-144.

17. Mitronikas, E.; Safacas, A. An improved sensorless vector-control method for an induction motor drive. IEEE Trans. Ind. Electron. 2005, 52, 1660-1668. [CrossRef]

18. Huang, S.; Liaw, C. Improved field-weakening control for IFO induction motor. IEEE Trans. Aerosp. Electron. Syst. 2003, 39, 647-659. [CrossRef]

19. Forestieri, J.; Farasat, M.; Trzynadlowski, A. Indirect Real- and Reactive-Power Control of Induction Motor Drives. IEEE J. Emerg. Sel. Top. Power Electron. 2018, 6, 2109-2125. [CrossRef] 
20. Uddin, M.; Wen, H. Development of a Self-Tuned Neuro-Fuzzy Controller for Induction Motor Drives. IEEE Trans. Ind. Appl. 2007, 43, 1108-1116. [CrossRef]

21. Mossa, M.; Bolognani, S. Effective sensorless model predictive direct torque control for a doubly fed induction machine. In Proceedings of the Nineteenth International Middle East Power Systems Conference (MEPCON), Cairo, Egypt, 19-21 December 2017; pp. 1201-1207.

22. Su, J.; Gao, R.; Husain, I. Model Predictive Control Based Field-Weakening Strategy for Traction EV Used Induction Motor. IEEE Trans. Ind. Appl. 2018, 54, 2295-2305. [CrossRef]

23. Riveros, J.; Barrero, F.; Levi, E.; Durán, M.; Toral, S.; Jones, M. Variable-Speed Five-Phase Induction Motor Drive Based on Predictive Torque Control. IEEE Trans. Ind. Electron. 2013, 60, 2957-2968. [CrossRef]

24. Mossa, M.; Bolognani, S. Effective model predictive direct torque control for an induction motor drive. In Proceedings of the International Symposium on Power Electronics, Electrical Drives, Automation and Motion (SPEEDAM), Capri, Italy, 22-24 June 2016; pp. 746-754.

25. Mossa, M. Effective predictive current control for a sensorless five-phase induction motor drive. Int. J. Power Electron. 2021, 13, 502-532. [CrossRef]

26. Xue, Y.; Meng, D.; Yin, S.; Han, W.; Yan, X.; Shu, Z.; Diao, L. Vector-Based Model Predictive Hysteresis Current Control for Asynchronous Motor. IEEE Trans. Ind. Electron. 2019, 66, 8703-8712. [CrossRef]

27. Mossa, M.; Bolognani, S. Robust Predictive Current Control for a Sensorless IM Drive Based on Torque Angle Regulation. In Proceedings of the IEEE Conference on Power Electronics and Renewable Energy (CPERE), Aswan, Egypt, 23-25 October 2019; pp. 302-308.

28. Wallscheid, O.; Ngoumtsa, E. Investigation of Disturbance Observers for Model Predictive Current Control in Electric Drives. IEEE Trans. Ind. Electron. 2020, 35, 13563-13572.

29. Mossa, M.; Bolognani, S. Effective model predictive current control for a sensorless IM drive. In Proceedings of the IEEE International Symposium on Sensorless Control for Electrical Drives (SLED), Catania, Italy, 18-19 September 2017 ; pp. 37-42.

30. Niu, L.; Yang, M.; Gui, X.; Xu, D. A comparative study of model predictive current control and FOC for PMSM. In Proceedings of the 17th International Conference on Electrical Machines and Systems (ICEMS), Hangzhou, China, 22-25 October 2014; pp. 3143-3147.

31. Zhang, Y.; Xia, B.; Yang, H.; Rodriguez, J. Overview of model predictive control for induction motor drives. Chin. J. Electr. Eng. 2016, 2, 62-76.

32. Arshad, M.; Abido, M.; Salem, A.; Elsayed, A. Weighting Factors Optimization of Model Predictive Torque Control of Induction Motor Using NSGA-II with TOPSIS Decision Making. IEEE Access 2019, 7, 177595-177606. [CrossRef]

33. Bhowate, A.; Aware, M.; Sharma, S. Predictive Torque Control with Online Weighting Factor Computation Technique to Improve Performance of Induction Motor Drive in Low Speed Region. IEEE Access 2019, 7, 42309-42321. [CrossRef]

34. Jin, X.; Zhang, Y.; Xu, D. Static Current Error Elimination Algorithm for Induction Motor Predictive Current Control. IEEE Access 2017, 5, 15250-15259. [CrossRef]

35. Scoltock, J.; Geyer, T.; Madawala, U. A Comparison of Model Predictive Control Schemes for MV Induction Motor Drives. IEEE Trans. Ind. Inform. 2013, 9, 909-919. [CrossRef]

36. Ertan, H.; Simsir, N. Comparison of PWM and PFM induction drives regarding audible noise and vibration for household applications. IEEE Trans. Ind. Appl. 2004, 40, 1621-1628. [CrossRef]

37. Yan, L.; Dou, M.; Hua, Z.; Zhang, H.; Yang, J. Robustness Improvement of FCS-MPTC for Induction Machine Drives Using Disturbance Feed forward Compensation Technique. IEEE Trans. Ind. Electron. 2019, 34, 2874-2886.

38. Devanshu, A.; Singh, M.; Kumar, N. An Improved Nonlinear Flux Observer Based Sensorless FOC IM Drive with Adaptive Predictive Current Control. IEEE Trans. Ind. Electron. 2020, 35, 652-666. [CrossRef]

39. Habibullah, M.; Lu, D. A Speed-Sensorless FS-PTC of Induction Motors Using Extended Kalman Filters. IEEE Trans. Ind. Electron. 2015, 62, 6765-6778. [CrossRef]

40. Cheng, L.; Tsai, M. Enhanced Model Predictive Direct Torque Control Applied to IPM Motor with Online Parameter Adaptation. IEEE Access 2020, 8, 42185-42199. [CrossRef]

41. Li, H.; Lin, J.; Lu, Z. Three Vectors Model Predictive Torque Control Without Weighting Factor Based on Electromagnetic Torque Feedback Compensation. Energies 2019, 12, 1393. [CrossRef]

42. Zhang, Y.; Yang, H.; Xia, B. Model predictive torque control of induction motor drives with reduced torque ripple. IET Electr. Power Appl. 2015, 9, 595-604. [CrossRef]

43. Zhang, Y.; Yang, H. Model-Predictive Flux Control of Induction Motor Drives with Switching Instant Optimization. IEEE Trans. Energy Convers. 2015, 30, 1113-1122. [CrossRef]

44. Abbasi, M.; Husain, A.; Idris, N.; Anjum, W.; Bassi, H.; Rawa, M. Predictive Flux Control for Induction Motor Drives with Modified Disturbance Observer for Improved Transient Response. IEEE Access 2020, 8, 112484-112495. [CrossRef]

45. Mossa, M.; Al-Sumaiti, A.; Do, T.; Diab, A. Cost-Effective Predictive Flux Control for a Sensorless Doubly Fed Induction Generator. IEEE Access 2019, 7, 172606-172627. [CrossRef]

46. Cirrincione, M.; Pucci, M.; Cirrincione, G.; Capolino, G. A new experimental application of least-squares techniques for the estimation of the induction motor parameters. IEEE Trans. Ind. Appl. 2003, 39, 1247-1256. [CrossRef] 
47. Orlowska-Kowalska, T. Application of extended Luenberger observer for flux and rotor time-constant estimation in induction motor drives. IEE Proc. D Control Theory Appl. 1989, 136, 324-330. [CrossRef]

48. Marino, R.; Peresada, S.; Tomei, P. On-line stator and rotor resistance estimation for induction motor. IEEE Trans. Control Syst. Technol. 2000, 8, 570-579. [CrossRef]

49. Ide, K.; Ha, J.; Sawamura, M.; Iura, H.; Yamamoto, Y. High frequency injection method improved by flux observer for sensorless control of an induction motor. In Proceedings of the Power Conversion Conference-Osaka (Cat. No.02TH8579), Osaka, Japan, 2-5 April 2002; pp. 516-521.

50. Liu, C.; Chang, H.; Wang, C. Very low speed sensorless control of induction motor drives using high-frequency signal injection. J. Chin. Inst. Eng. 2005, 28, 957-966. [CrossRef]

51. Karanayil, B.; Rahman, M.; Grantham, C. Implementation of an on-line resistance estimation using artificial neural networks for vector controlled induction motor drive. In Proceedings of the IECON'03. 29th Annual Conference of the IEEE Industrial Electronics Society (IEEE Cat. No. 03CH37468), Roanoke, VA, USA, 2-6 November 2003; Volume 2, pp. $1703-1708$.

52. Mossa, M.; Vu, Q.; Echeikh, H.; Do, T. Deadbeat-Based Model Predictive Voltage Control for a Sensorless Five-Phase Induction Motor Drive. Math. Probl. Eng. 2020, 2020, 4164526. [CrossRef]

53. Kojabadi, H.; Chang, L.; Doraiswami, R. A MRAS-based adaptive pseudoreduced-order flux observer for sensorless induction motor drives. IEEE Trans. Ind. Electron. 2005, 20, 930-938. [CrossRef]

54. Ohyama, K.; Asher, G.; Sumner, M. Comparative analysis of experimental performance and stability of sensorless induction motor drives. IEEE Trans. Ind. Electron. 2006, 53, 178-186. [CrossRef]

55. Kanellakopoulos, I.; Kokotovic, P.; Morse, A. Systematic design of adaptive controllers for feedback linearizable systems. IEEE Trans. Autom. Control 1991, 36, 1241-1253. [CrossRef]

56. Kokotovic, P. The joy of feedback: Nonlinear and adaptive. IEEE Control Syst. Mag. 1992, 12, 7-17.

57. Lozano-Leal, R.; Brogliato, B. Adaptive Control of Robot Manipulators with Flexible Joints. In Proceedings of the American Control Conference, Los Angeles, CA, USA, 4-7 November 1991; pp. 938-943.

58. Arbin, E.; Gregory, M. Adaptive Backstepping Control of a Speed Sensorless Induction Motor under Time-Varying Load Torque and Rotor Resistance Uncertainty. In Proceedings of the 38th Southeastern Symposium on System Theory, Cookeville, TN, USA, 4-6 March, 2006; pp. 512-518.

59. Hwang, Y.; Park, K.; Yang, H. Robust adaptive backstepping control for efficiency optimization of induction motors with uncertainties. In Proceedings of the IEEE International Symposium on Industrial Electronics, Cambridge, UK, 30 June-2 July 2008; pp. 878-883.

60. Tan, Y.; Chang, J.; Tan, H. Adaptive backstepping control and friction compensation for AC servo with inertia and load uncertainties. IEEE Trans. Ind. Electron. 2003, 50, 944-952.

61. Yan, L.; Dou, M.; Zhang, H.; Hua, Z. Speed-Sensorless Dual Reference Frame Predictive Torque Control for Induction Machines. IEEE Trans. Ind. Electron. 2019, 34, 12285-12295. [CrossRef]

62. Davari, S.; Nekoukar, V.; Garcia, C.; Rodriguez, J. Online Weighting Factor Optimization by Simplified Simulated Annealing for Finite Set Predictive Control. IEEE Trans. Ind. Inform. 2020, 17, 31-40. [CrossRef] 